\title{
Stock Prices and Economic Activity in the Time of Coronavirus
}

\author{
Steven J. Davis ${ }^{1}$. Dingqian $\mathrm{Liu}^{2} \cdot$ Xuguang Simon Sheng ${ }^{2}$ \\ Published online: 13 September 2021 \\ (C) International Monetary Fund 2021
}

\begin{abstract}
Stock prices and workplace mobility trace out striking clockwise paths in daily data from mid-February to late May 2020. Global stock prices fell $30 \%$ from 17 February to 12 March, before mobility declined. Over the next 11 days, stocks fell another 10 percentage points as mobility dropped 40\%. From 23 March to 9 April, stocks recovered half their losses and mobility fell further. From 9 April to late May, both stocks and mobility rose modestly. This dynamic plays out across the 35 countries in our sample, with notable departures in China, South Korea and Taiwan. The size of the global stock market crash in reaction to the pandemic is many times larger than a standard asset-pricing model implies. Looking more closely at the world's two largest economies, the pandemic had greater effects on stock market levels and volatilities in the USA than in China even before it became evident that early US containment efforts would flounder. Newspaper-based narrative evidence confirms the dominant-and historically unprecedented-role of pandemic-related developments in the stock market behavior of both countries.
\end{abstract}

JEL Classification E32 $\cdot$ E44 $\cdot$ E65 $\cdot \mathrm{G} 12 \cdot \mathrm{G} 18 \cdot \mathrm{I} 18$

Steven J. Davis

Steven.Davis@chicagobooth.edu

Dingqian Liu

d15165a@american.edu

Xuguang Simon Sheng

sheng@american.edu

1 Booth School of Business, University of Chicago, Chicago, USA

2 Department of Economics, American University, Washington, USA 


\section{Introduction}

Stock markets around the world cratered after mid-February 2020, as the coronavirus pandemic spread beyond China. Value-weighted prices dropped $40 \%$ from 17 February to 23 March in the advanced economies (Fig. 1). Emerging market and developing economies (EMDEs) saw an even steeper drop. This period also exhibits historically high levels of intraday, daily and implied stock market volatilities against a backdrop of extreme economic uncertainty. ${ }^{1}$ Globally, the market recovered more than half its losses from 23 March to late May. The US market recovered $73 \%$ of its losses by the end of May 2020 and $95 \%$ by 22 July. $^{2}$

Recent stock market behavior is also remarkable in other respects. Using textbased methods to characterize the drivers of stock market jumps and volatility, Baker et al. (2020a) find that previous pandemics, including the Spanish Flu, had modest effects on the US market. In one exercise, they examine all 1143 daily US stock market moves greater than $2.5 \%$, up or down, since 1900 . Next-day newspaper accounts attribute not a single jump before 2020 to pandemic-related developments. In glaring contrast, newspapers attribute 24 of 27 daily US jumps between 24 February and 30 April 2020 to COVID-19 and policy responses. ${ }^{3}$

Our first goal in this paper is to document some striking patterns in the temporal relationship of stock prices to economic activity in the early stages of the COVID19 pandemic. We do so by examining daily movements in national stock prices and economic activity in 35 countries around the world. Stock prices and workplace mobility (a proxy for economic activity) trace out clockwise paths in daily data from mid-February to late May 2020. Global stock prices fell 30\% from 17 February to 12 March, before mobility declined. Over the next 11 days, stocks fell another 10 percentage points as mobility dropped $40 \%$. From 23 March to 9 April, stocks recovered half their losses and mobility fell further. From 9 April to late May, mobility rose modestly and stocks recovered further. The same dynamic plays out across the vast majority of the 35 countries in our sample, with a few notable exceptions that we highlight and discuss.

Common global dynamics are a pronounced feature of our data. Thus, we also ask whether national stock prices have predictive value for own-country economic

\footnotetext{
1 See Alan et al. (2020) for equity market volatility measures based on GARCH models and intraday prices for dozens of countries, Baker et al. (2020a) for US volatility measures that stretch back to 1900, the website at www.PolicyUncertainty.com for newspaper-based economic uncertainty measures for more than 25 countries based on Baker et al. (2016), and Altig et al. (2020) for a variety of forwardlooking measures of economic uncertainty for the USA and United Kingdom.

2 Calculated from the Wilshire 5000 Total Market Full Cap Index [WILL5000INDFC], retrieved from FRED, Federal Reserve Bank of St. Louis on 25 July 2020. Because US markets were closed on 17 February, our start date is 18 February in these calculations.

3 Other works that highlight stock market responses to the pandemic include Alfaro et al. (2020), who find that changes in the anticipated trajectory of COVID-19 infections predict next-day US stock returns; Amstad et al. (2020), who find that a "COVID-19 risk attitude" index derived from internet searches helps explain national stock market moves from mid-February to late April; and Alan et al. (2020), who find that the number of active COVID-19 cases and the curvature of the active-case trajectory help predict stock market volatilities in a cross section of countries.
} 


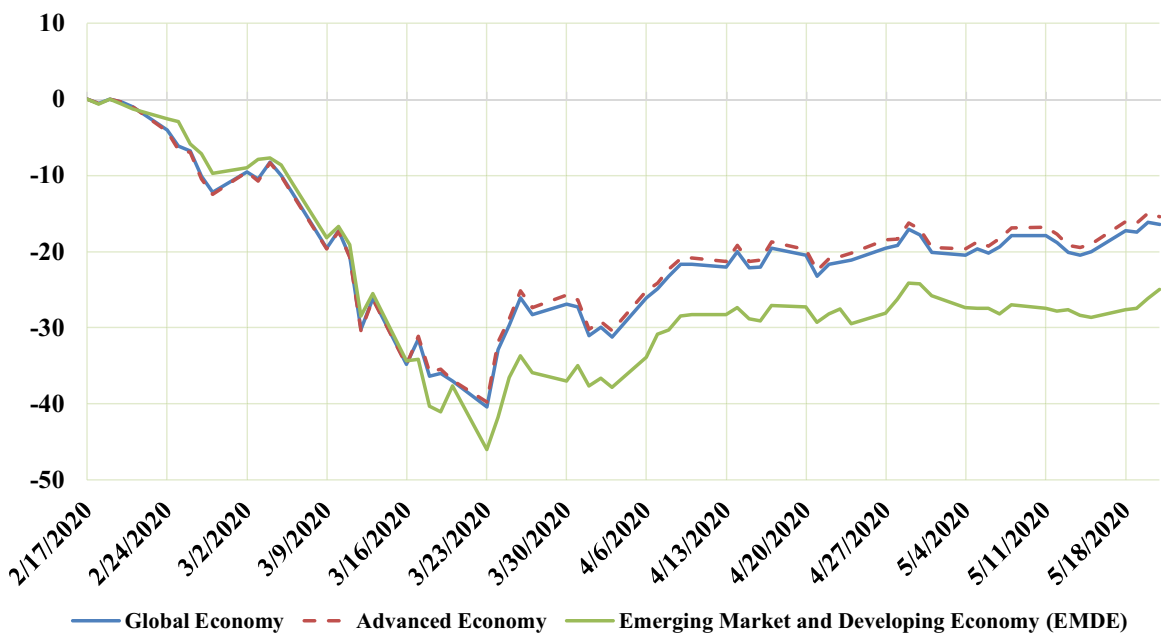

Fig. 1 Global stock prices, percent deviations from 17 February 2020. Notes: We plot the cumulative percent deviation in average equity prices from 17 February 2020 to the indicated dates. In computing averages, we weight each country's deviation by its market capitalization on 31 December 2018. Before averaging, we linearly interpolate country-level values between nearest trading dates to fill in missing values. The sample for this figure contains 20 advanced economies (89\% of overall market capitalization) and 14 EMDEs according to IMF's classification. We omit China in this plot but show it separately below

activity in the early stages of the pandemic, conditional on global developments. They do. Another natural question is whether stock prices responded too slowly to information that presaged a pandemic-driven downturn. While we cannot rule out this possibility, we make several observations that suggest it was reasonable, as of early and mid-February 2020, for investors to anticipate a modest impact of COVID19 on economic activity and asset prices.

After establishing that stock prices foreshadowed the pandemic-related drop in economic activity, we ask whether the size of the market crash is proportionate to the pandemic's prospective economic impact. We show that the market crash was many times larger than a standard asset-pricing model implies. In this light, the dramatic recovery of USA and global stock prices from late March onwards can be seen as correcting the market's initial overreaction to news about fundamentals, as gauged by the implications of a standard model.

We also consider China's distinctive pandemic experience in comparison with that of the USA and in relation to countries with successful early-stage responses. Perhaps because COVID-19 erupted first in China, the dynamic between stock prices and mobility played out differently there. In particular, China experienced coincident drops in stock prices and mobility during the early phase of its pandemic recession. Unlike most other countries, our mobility measure for China returns to its pre-pandemic baseline by late April, and Chinese stock prices surpass pre-pandemic levels by the second half of April. We also show that the COVID-19 pandemic had 
much smaller effects on stock prices and return volatilities in China than in the USA. The US market shows greater sensitivity to pandemic-related developments well before it became evident that its early containment efforts would flounder.

Using next-day newspaper accounts, we also classify the (perceived) reasons for large daily moves in Chinese stock markets from 1990 onwards. Before COVID-19, leading Chinese newspapers attribute not a single such move (out of hundreds) to pandemic developments or news about infectious diseases. From 2 January to 30 April 2020, Chinese newspapers attribute all 6 daily stock market moves greater than $13 \%$ on the Shanghai Stock Exchange and all 8 daily moves greater than $13.8 \% \mid$ on the Hang Seng to the economic fallout of the pandemic or policy responses to it. ${ }^{4}$ These results closely parallel findings in Baker et al. (2020a) for the USA, but the incidence of large daily moves in the US stock market during the coronavirus pandemic is about four times greater.

Our study relates closely to a growing literature on the dynamics of stock prices, economic activity, and policy actions during the coronavirus pandemic. In addition to papers mentioned above, notable contributions include Caballero and Simsek (2021), Cox et al. (2020), Deb et al. (2020), Giglio et al. (2021), Gormsen and Koijen (2020), Landier and Thesmar (2020) and Zarembra et al. (2020). ${ }^{5}$ Relative to this literature, we contribute in several ways: First, by documenting the predictive content of national stock prices for near-future economic activity in the early stages of the pandemic. Second, by showing that the market crash in reaction to the pandemic is too large to be rationalized by a standard asset-pricing model. Third, by developing several pieces of evidence on the distinctive character of the Chinese stock market reaction to the pandemic, highlighting both contrasts and similarities to the US case. Fourth, by identifying other countries with distinctively favorable early-pandemic experiences and contrasting key aspects of their COVID-19 policy responses to that of China.

\section{Stock Prices and Economic Activity as the Pandemic Unfolded}

\subsection{Sources of Data for National Outcomes}

We integrate data from multiple sources. Our high-frequency proxy for national economic activity is the percent workplace mobility deviations from baseline in Google's COVID-19 Community Mobility Reports. This measure reflects the frequency

\footnotetext{
${ }^{4}$ One might worry that newspaper accounts merely reflect the prevailing narrative of the day rather than meaningful information about the true reasons for large daily stock market moves. Baker et al. (2020b) address this issue by validating their newspaper-derived explanations in several ways. They also find that newspaper-based interpretations help predict future stock market volatility, even when conditioning on a standard battery of controls for serial correlation in stock market volatility.

5 Another rapidly growing literature explores the distinctive effects of the coronavirus pandemic on the cross-sectional structure of firm-level equity returns. Examples include Albuquerque et al. (2020), Alfaro et al. (2020), Davis et al. (2020), Ding et al. (2020), Hassan et al. (2020), Pagano et al. (2020), Papanikolaou and Schmidt (2020), and Ramelli and Wagner (2020).
} 
and duration of visits to worksites relative to the own-country baseline. Google (2020) defines the baseline as the median value, for the corresponding day of the week, during the 5-week period from 3 January to 6 February 2020. These data are available from 17 February onwards for 34 countries in our many-country sample but not for China. Figure 13 plots the relationship between real GDP growth and our workplace mobility deviation in a cross section of countries. ${ }^{6}$

We obtain national stock market index values on trading days from Global Financial Data (GFD) at https://globalfinancialdata.com/ and other sources. For much of our analysis, we treat each country's value on 17 February 2020 as a baseline and measure percent deviations on date $t$ as $r_{c, t}=\ln \left(\frac{P_{c, t}}{P_{c, 0}}\right) \times 100$, where $P_{c, 0}$ is the stock market index value of country $c$ on 17 February. When aggregating over countries, we weight by stock market capitalization values as of 31 December 2018 from the World Bank's World Federation of Exchanges Database.

After merging these sources, we have daily data for 34 countries from 17 February to 21 May 2020. Ordered by stock market capitalization, there are 20 Advanced Economies (AE) in our sample: The USA, Japan, United Kingdom, France, Canada, Switzerland, Germany, Australia, South Korea, Netherlands, Spain, Singapore, Sweden, Belgium, Taiwan, Poland, Ireland, New Zealand, Greece, Slovenia. There are 14 EMDEs: India, Brazil, South Africa, Thailand, Malaysia, Mexico, Chile, Qatar, Turkey, Romania, Argentina, Kazakhstan, Hungary, Croatia. ${ }^{7}$ We also have stock price data for China, which we merge to a different source of data on mobility, as discussed below.

Figure 2 displays percent workplace mobility deviations (WMD) for selected countries and regions. We linearly interpolate WMD values between market trading days to remove the effects of weekends and holidays (Fig. 14 displays raw values). Most countries experienced tremendous drops in economic activity after early March. From 9 March to 9 April, the weighted-average WMD value fell nearly half among the AEs and nearly 60\% among the EMDEs. Figure 2 also shows the WMD path for three "outlier" countries with relatively small drops in economic activity: Japan, Sweden and South Korea.

Figures 3 and 15 summarize the stringency of market lockdown measures adopted by governments in reaction to the pandemic, as quantified in Hale et al. (2020). These figures show that the timing and severity of lockdowns differ substantially across countries. The pandemic emerged first in China, and China also clamped down on economic activity sooner than other countries. South Korea, Japan and Taiwan also responded faster than most other AEs but more lightly in Japan and Taiwan. Sweden responded later than other AEs and with relatively light restrictions. Except for Japan, Sweden and Taiwan, all countries in our sample eventually

\footnotetext{
${ }^{6}$ As Egert et al. (2020) show, workplace mobility moves very similarly to other mobility measures such as those that focus on transit stations, grocery stores and pharmacies, and retail establishments. They also confirm that Google mobility measures correlate highly with aggregate activity in the first half of 2020, as measured by quarterly GDP forecast revisions. Sampi and Jooste (2020) and Chen and Spence (2020) also show that mobility-based measures proxy well for standard measures of economic activity.

7 Our grouping follows the IMF at www.imf.org/external/pubs/ft/weo/2020/01/weodata/groups.htm.
} 


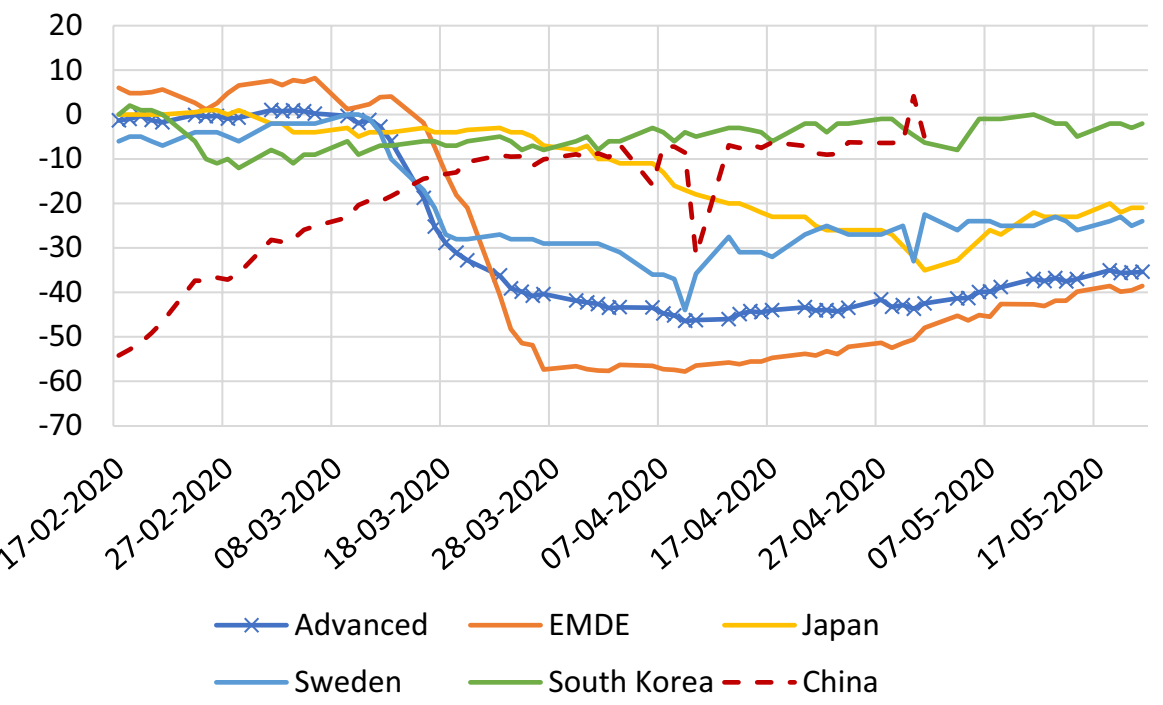

Fig. 2 Workplace mobility on trading days, percent deviation from baseline. Note: We obtain national data from Google (2020) for trading days, interpolate the national data between trading days, and aggregate over countries using stock market capitalization. China's mobility data are from Baidu. China is not included in either Advanced economy or EMDE

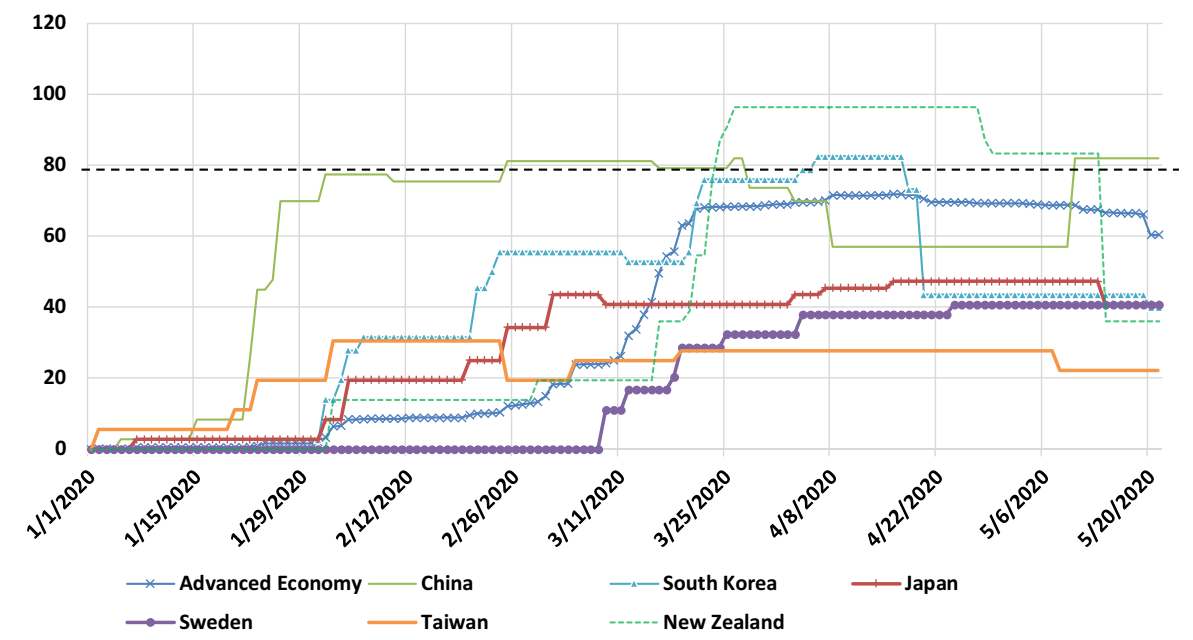

Fig. 3 Economic lockdown stringency index, 1 January to 21 May 2020. Note: Data are from Hale et al. (2020) and aggregated using stock market capitalization. The stringency index exceeds 70 at some point for all countries except Japan, Sweden and Taiwan

implemented a hard lockdown for at least one week, where we interpret "hard" to mean a lockdown stringency index value of 70 or greater. 


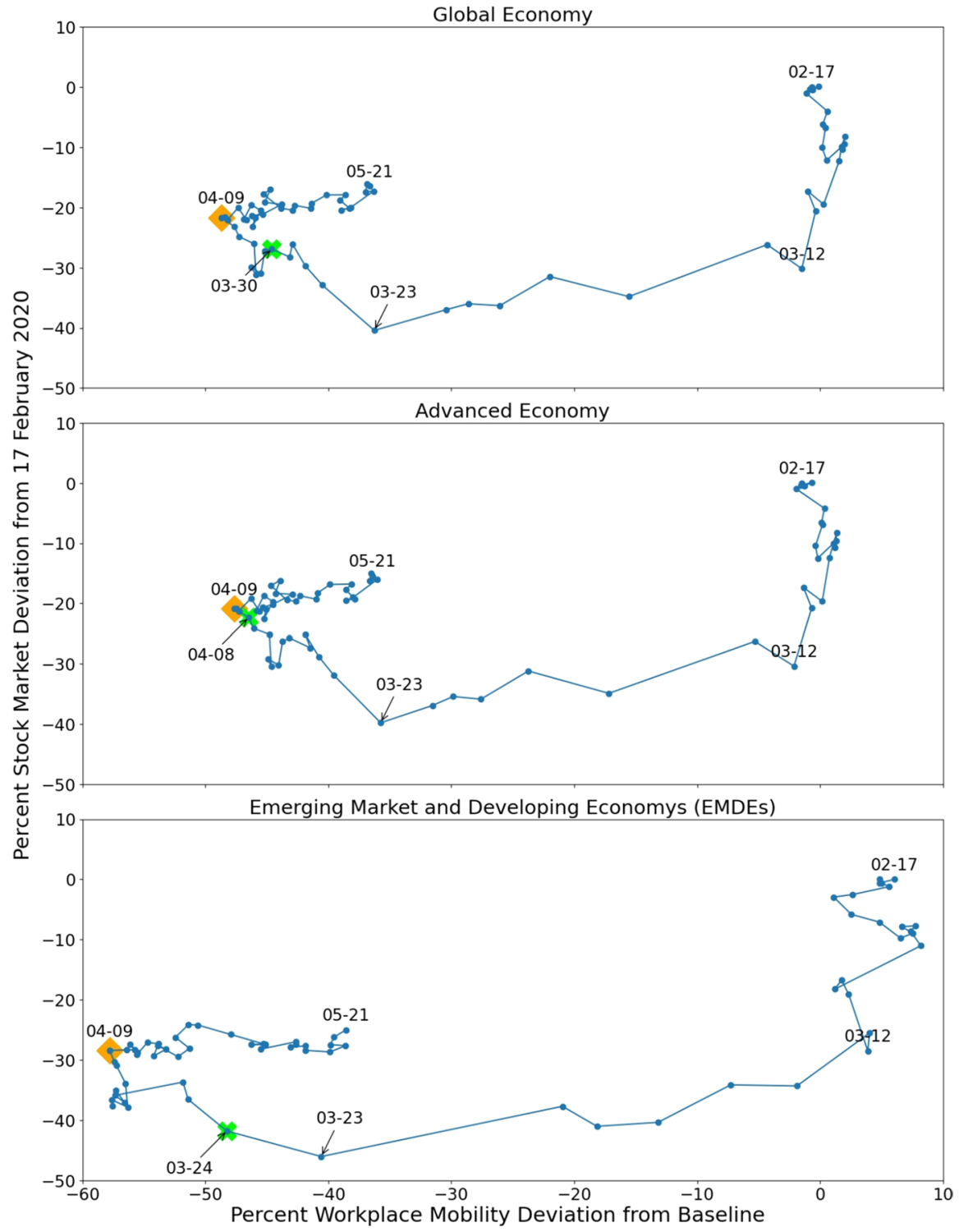

Fig. 4 Time path of stock prices and workplace mobility from 17 February to 21 May 2020. Note: The orange diamond marker highlights the date when the (weighted) global workplace mobility deviation from baseline reached its lowest value. The green cross highlights the first date when the weighted average lockdown stringency index first exceeds 70

\subsection{The Time Paths of Stock Prices and Economic Activity}

Figure 4 shows that stock prices and workplace mobility trace out striking clockwise paths in daily data from mid-February to late May 2020. Global stock prices 


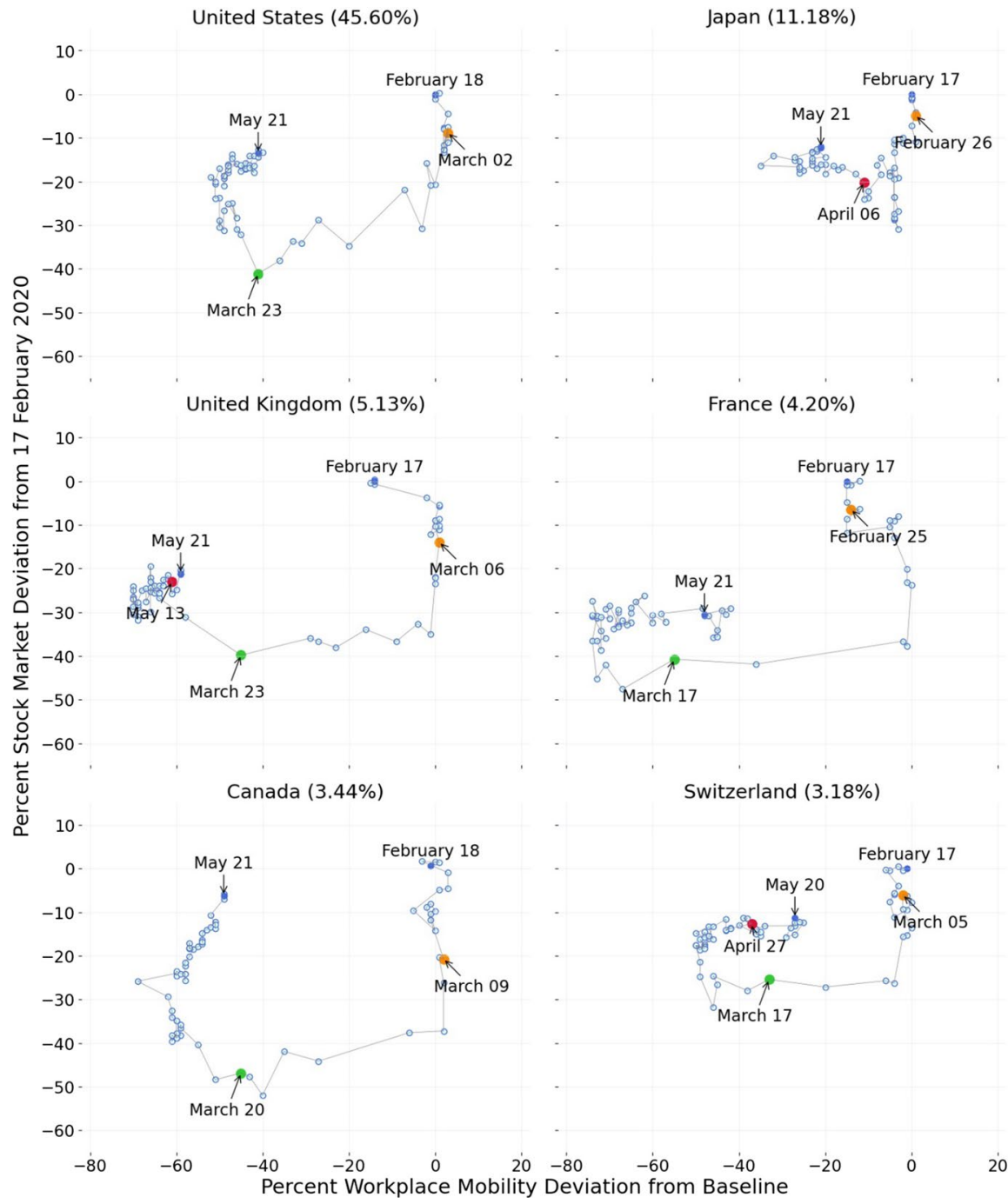

Fig. 5 Time path of stock prices and workplace mobility from 17 February to 21 May, Advanced Economies and EMDEs with Largest Market Capitalization (in parentheses). Note: An orange dot marks the first confirmed COVID-19 death in the country, a green dot marks the first date with a stringency index value of 70 or more, and a red dot marks the date on which the stringency index first drops below 70

fell $30 \%$ from 17 February to 12 March, before mobility declined. Over the next 11 days, stocks fell another 10 percentage points as mobility dropped $40 \%$. From 23 March to 9 April, stocks recovered half their losses and mobility fell further. From 9 April to late May, both stocks and mobility rose modestly. The same dynamic plays out across the vast majority of the 35 countries in our sample (Figs. 5 and 16), with a few notable exceptions that we discuss later. 
$20-$
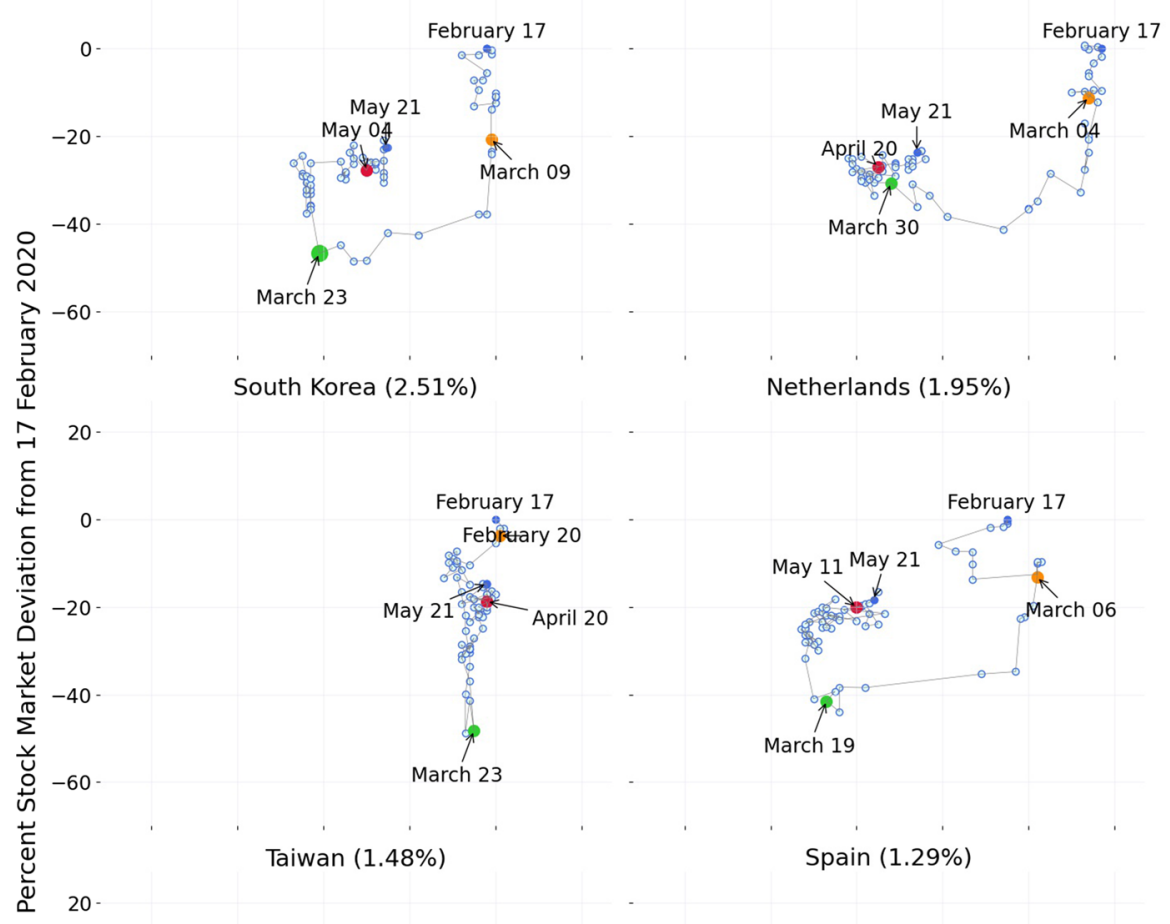

Netherlands (1.95\%)

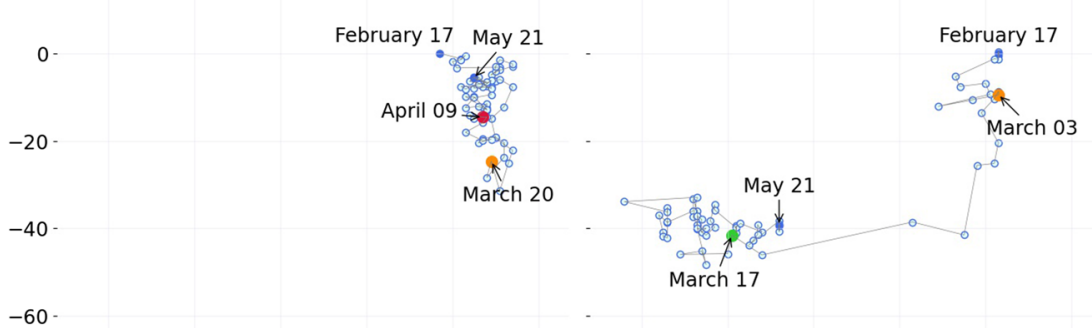

$-60-$

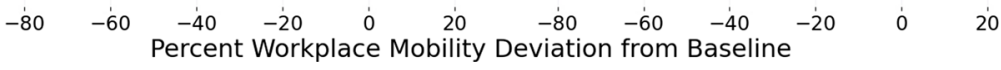

Fig. 5 (continued)

While our evidence shows that collapsing stock prices clearly preceded the collapse in economy activity, one could argue that a rational, forward-looking stock market would have reacted sooner. Indeed, Shiller (2020) writes: "[T]he World Health Organization (WHO) declared the new coronavirus 'a public health emergency of international concern' on January 30. Over the next 20 days, the S\&P 500 rose by $3 \%$, hitting an all-time record high on February 19 . Why would investors give shares their highest valuation ever right after the announcement of 


\section{Singapore (1.22\%)}

20 -
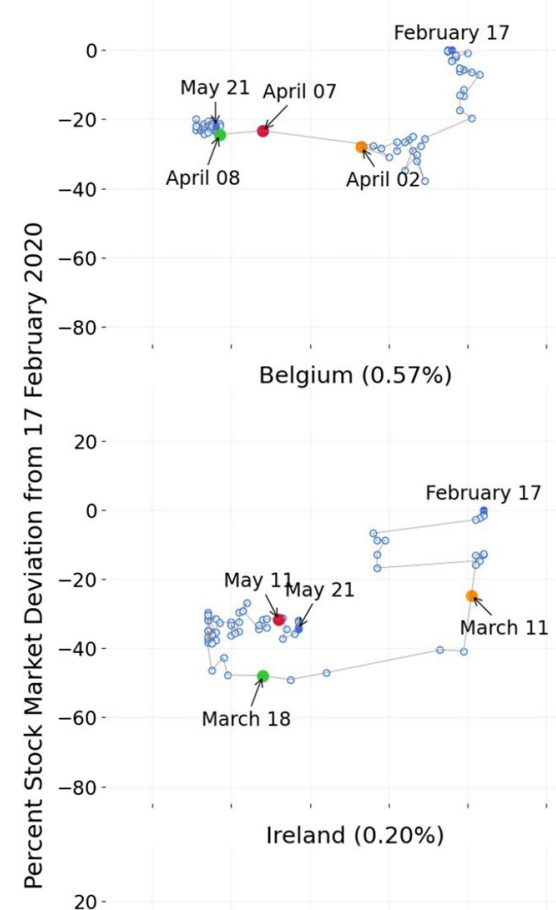

20 -

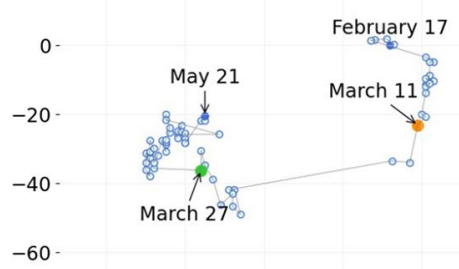

$-80$
Sweden (1.12\%)

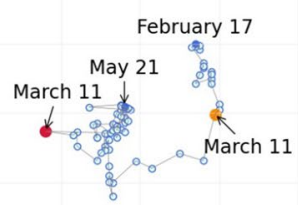

Poland $(0.29 \%)$

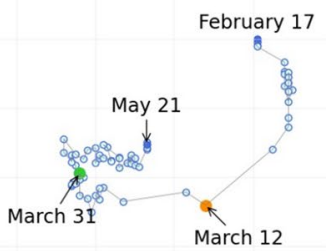

New Zealand $(0.15 \%)$

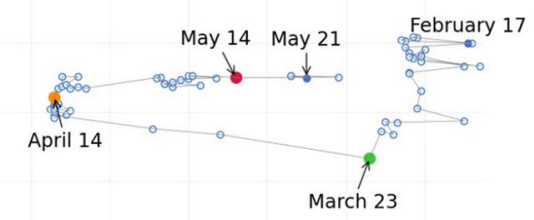

Fig. 5 (continued)

a possible global tragedy? ... Why didn't the stock market "predict" the coming recession by declining before the downturn started?"

We take Shiller's question to be why didn't stock markets react earlier to the possibility of an impending economic disaster? And, in particular, why didn't markets react shortly after the WHO's declaration on 30 January? There is a ready answer to this question: Most investors did not see the novel coronavirus as a major risk to the economy of the sort that warranted a large devaluation in 
equity prices. Moreover, it is not obvious as of early February 2020, except in hindsight, that they should have regarded the virus as a major economic risk.

In this regard, we make four sets of observations. First, the WHO declared a "public health emergency of international concern" on five prior occasions since $2009 .{ }^{8}$ None of these declarations triggered a market crash, nor did any of the underlying disease outbreaks unfold in a manner that warranted a major drop in equity prices. Second, Baker et al. (2020a) show that no infectious disease outbreak in the previous 120 years affected the US stock market in a manner that resembles its response to COVID-19. That includes the Spanish Flu of 1918-19, which involved a US excess mortality rate about three times greater than COVID-19 to date. It also includes the influenza pandemic of 1957-58, which involved a US excess mortality rate more than one-third that of COVID-19 to date. ${ }^{9}$ Third, we provide evidence below that no previous infectious disease outbreak (back to 1990) affected stock markets in mainland China and Hong Kong in a manner that resembles their responses to COVID-19. That includes the SARS outbreak in 2003. Fourth, at least in the USA, the economic contraction triggered by COVID-19 has been much sharper than one would anticipate by extrapolating the impact of previous pandemics over the past 120 years. ${ }^{10}$ These observations suggest it was reasonable, as of early and even midFebruary 2020, for stock market investors to anticipate a modest economic impact of COVID-19 on economic activity and asset prices.

\subsection{National Stock Prices Predict Country-Specific Drops in Economic Activity}

As we have seen, common global dynamics are a pronounced feature of stock prices, workplace mobility and lockdown stringency measures during the period in which global-average values collapse. ${ }^{11}$ That raises the question of whether national stock prices have predictive value for own-country economic activity, conditional on global developments. We take up that question now.

To do so, we regress workplace mobility deviations on lagged stock price deviations in our panel of 34 countries. Our sample for this analysis contains all workdays from 12 March to 23 March, where "workdays" refer to dates on which the country's stock market traded. For explanatory variables, we linearly interpolate between trading days to fill in weekend and holiday values. We choose 23 March as the sample endpoint for this analysis, because that is when stock prices in most countries began to increase even as mobility fell further. We run two sets of regression:

\footnotetext{
${ }^{8}$ See the Wikipedia entry for public health emergency of international concern, accessed 12 October 2020. The WHO formalized this type of emergency announcement in 2005, as discussed in WHO (2005).

9 See Baker et al. (2020a) for our excess mortality data sources and calculations. Here, we use an updated figure of 597,490 excess US deaths from 7 March 2020 through 16 March 2021.

10 See Baker et al. (2020a), Ferguson (2020), and Velde (2020) on this point.

11 Regressing national stock price deviations from 17 February to 21 May on a full set of day fixed effects yields an adjusted R-squared value of 0.85. Analogous regressions yield an adjusted R-squared value of 0.85 for workplace mobility deviations, 0.94 for the stringency of market lockdown measures, and 0.24 for COVID-19 deaths per million persons (deaths data from Johns Hopkins University 2020).
} 
Table 1 Regressions of workplace mobility deviations on lagged stock price deviations, daily countrylevel data from 12 March to 23 March for the dependent variable $\mathrm{WMD}_{c, t}=$ percent workplace mobility deviation in country $c$ on trading day $t, \mathrm{SMD}_{c, t}=$ percent stock price deviation in country $c$ on trading day $t, \Delta \mathrm{WMD}_{c, t}=\mathrm{WMD}_{c, t}-\mathrm{WMD}_{c, t-1}$

\begin{tabular}{|c|c|c|c|c|c|c|}
\hline \multirow[t]{2}{*}{ Coefficient estimates } & \multicolumn{4}{|c|}{ Dependent variable: $\mathrm{WMD}_{\mathrm{c}, \mathrm{t}}$} & \multicolumn{2}{|c|}{$\begin{array}{l}\text { Dependent variable: } \\
\Delta \mathrm{WMD}_{c, t}\end{array}$} \\
\hline & (1) & (2) & (3) & (4) & (5) & (6) \\
\hline$\alpha$ & $\begin{array}{l}0.86 * * * \\
(0.09)\end{array}$ & $\begin{array}{l}0.85 * * * \\
(0.09)\end{array}$ & $\begin{array}{l}0.37 * * * \\
(0.08)\end{array}$ & $\begin{array}{l}-0.05 \\
(0.10)\end{array}$ & & \\
\hline$\sum_{j=1}^{6} \beta^{j}$ & & & & & $\begin{array}{l}1.50 * * * \\
(0.33)\end{array}$ & $\begin{array}{l}1.07 * * * \\
(0.33)\end{array}$ \\
\hline Intercept & $\begin{array}{l}8.22 * * \\
(3.35)\end{array}$ & & & & $\begin{array}{l}-0.56 \\
(1.15)\end{array}$ & \\
\hline Country fixed effects & No & Yes & No & Yes & No & No \\
\hline Time fixed effects & No & No & Yes & Yes & No & Yes \\
\hline Observation count & 265 & 265 & 265 & 265 & 265 & 265 \\
\hline Adjusted $R^{2}$ & 0.24 & 0.77 & 0.66 & 0.90 & 0.18 & 0.49 \\
\hline
\end{tabular}

The sample includes all workdays from 12 March to 23 March for 34 countries, where "workdays" refers to dates on which the country's stock market traded. For explanatory variables, we linearly interpolate between trading days to fill in weekend and holiday values. We use country-level stock price deviations prior to 12 March for lagged values of the explanatory variables. OLS Standard errors in parentheses

$* p<.1 ; * * p<.05 ; * * * p<.01$

$$
\begin{gathered}
\mathrm{WMD}_{c, t}=\alpha \times \mathrm{SMD}_{c, t-1}+I_{c}+I_{t}+\varepsilon_{c, t} \\
\Delta \mathrm{WMD}_{c, t}=\sum_{j=1}^{6} \beta^{j} \times \Delta \mathrm{SMD}_{c, t-j}+I_{t}+\varepsilon_{c, t}
\end{gathered}
$$

Table 1 reports the results. The first three columns provide strong statistical evidence that lower national stock prices yesterday foreshadow lower own-country workplace mobility deviations today. To interpret magnitudes, consider Column (3). The coefficient on the lagged own-country $S M D$ variable says: If yesterday's national stock price is 10 percentage points below its baseline value, the model predicts that today's mobility deviation is 3.7 percentage points below its baseline, conditional on common global developments. This is a large effect, especially in light of the fact that many countries in our sample experienced $S M D$ values 30 percentage points or more below baseline as of 22 March. $^{12}$

\footnotetext{
12 Column (4) shows a statistically insignificant coefficient on lagged SMD when controlling for country and time effects. Since our sample entails a short panel dimension, with at most 8 observations per country, the inclusion of country and time effects pushes the data very hard. In this regard, recall that both $S M D$ and $W M D$ are already demeaned at the country level, since they are expressed relative to countryspecific baselines. So, we do not think Column (4) is particularly informative. We include it here in case the reader has a different view.
} 
Columns (5)-(6) implement versions of regression (2) and confirm the predictive power of national stock prices for own-country economic activity during the midMarch period. In particular, the results say that changes in stock prices over the previous six days predict same direction changes in today's economic activity. To interpret magnitudes, consider Column (6). The results say that a one-percentage drop in national stock prices on each of the previous six trading days predicts a 6.4 percentage point drop in today's economic activity, as measured by $W M D$, conditional on common global developments. This is also a large effect. Table 4 shows that we obtain very similar results when using mobility deviations for transit stations, or for retail and recreation outlets, as our proxy for economic activity.

\subsection{Can a Standard Asset-Pricing Model Rationalize the Size of the Market Crash?}

We now consider whether a standard asset-pricing model can rationalize the size of the stock market crash depicted in Figs. 1, 4 and 5. We work with the rare-disaster model of Barro (2006), who builds on Lucas (1978), Mehra and Prescott (1985), and Rietz (1988). ${ }^{13}$ Earlier work using this type of model typically focuses on its implications for expected returns and the (expected) equity premium relative to the risk-free return. In contrast, we consider the model's implications for realized equity returns in reaction to an actual disaster.

Barro (2006) posits an endowment economy with a representative agent who has time-separable, isoelastic preferences over the consumption good. Log output evolves exogenously as a random walk with drift:

$$
\ln \left(A_{t+1}\right)=\ln \left(A_{t}\right)+\gamma+u_{t+1}+v_{t+1},
$$

where the drift $\gamma \geq 0, u_{t+1}$ is i.i.d. normal with mean 0 and variance $\sigma^{2}$, and $v_{t+1}$ picks up low-probability disaster shocks. Barro shows that the price of a one-period equity claim at $t$ is

$$
P_{t 1}=A_{t} e^{-\rho-(\theta-1) \gamma+(1 / 2)(\theta-1)^{2} \sigma^{2}} \times\left[e^{-p}+\left(1-e^{-p}\right) \times \mathrm{E}\left\{(1-b)^{1-\theta}\right\}\right],
$$

where $\rho$ is the rate of time preference, $\theta$ is relative risk aversion, $\sigma$ is the standard deviation of the output growth rate absent disasters, E denotes the expectations operator, $p$ is the disaster probability, and $b$ is the size of the $\log$ output drop when disaster strikes. Disaster size is a random variable, which Barro calibrates to the empirical distribution of national economic disasters in the twentieth century. $\gamma, \sigma, p$ and other model parameters are known.

\footnotetext{
13 Mehra and Prescott (1985) highlighted the equity return premium as a major puzzle for the standard representative-agent asset-pricing model set forth by Lucas (1978). Rietz (1988) showed that the puzzle could be resolved by allowing for a small probability of sufficiently big economic disasters. Barro (2006) advanced this idea by developing evidence on the frequency and size of economic disasters, calibrating an otherwise standard asset-pricing model to his evidence, and showing that it could rationalize the historical equity premium. Barro's article spurred many other investigations into the asset-pricing implications of rare disasters. See, for example, Gabaix (2012) and Wachter (2013) and references therein.
} 


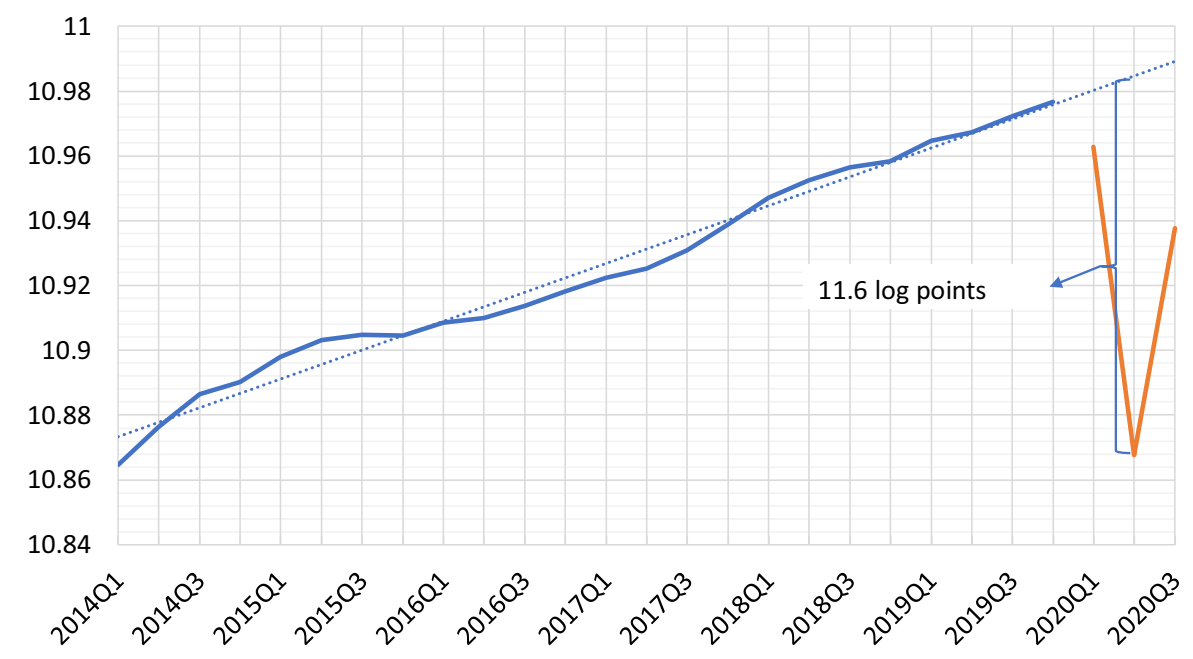

Fig. 6 Assessing the size of the COVID-19 disaster. Note: The solid lines show real GDP per capita (from FRED) plotted in natural log units from 2014 Q1 to 2019 Q4 (solid blue line) and 2020 Q1 to 2020 Q3 (orange line). The dashed line shows a linear fit to the pre-pandemic data and its extrapolation to the post-pandemic period. The maximal gap between the dashed and orange curves of $11.6 \log$ points which occurs in 2020 Q2

In taking this model to the data, we interpret 17 February as the last date before disaster strikes and 23 March as the date by which agents fully understand the gravity of the disaster. Global and US equity prices fell about 40\% (51 log points) over this 33-day period. Using (3) and (4), the model-implied realized equity return over this period is

$$
\ln \left(\frac{P_{\text {after }}}{P_{\text {before }}}\right)=\ln \left(\frac{A_{\text {after }}}{A_{\text {before }}}\right)=\gamma\left(\frac{33}{365}\right)+u_{1}-\left|v_{1}\right|,
$$

where $\mid v_{1}$ lis the realized disaster size, and $u_{1}$ is the realized value of the regular shock. ${ }^{14}$ For any reasonable values of the annual drift $(\gamma)$ and the variability of regular shocks $(\sigma)$, the first two terms on the right side of (5) are tiny compared to $v_{1}$ Thus, the model implies that stock prices fall nearly one-for-one in proportion to disaster size.

Figure 6 helps gauge the size of the COVID-19 disaster. The dashed line shows a $\log$ linear fit to data on US real GDP per capita from 2014 Q1 through 2019 Q4 and its extrapolation through 2020 Q3. The maximal gap between the extrapolation and the actual path of real GDP per capita is about $12 \log$ points. We see this maximal gap as a loose upper bound on the perceived size of the disaster, given widespread expectations of rapid recovery once the pandemic comes under control and the strong partial bounce back actually seen in 2020 Q3. Evidence based on investor

$\overline{14}$ Given the stochastic process in (3), rates of return on one-period and full equity claims are identical. 
beliefs in Giglio et al. (2021), dividend strips in Gormsen et al. (2020) and projected corporate earnings in Landier and Thesmar (2020) all point to a disaster that is considerably smaller than $12 \log$ points. In short, the evidence says the stock market crash was at least four times the size of the worst-case output collapse occasioned by the COVID pandemic and perhaps ten times as large. Thus, the model cannot explain the size of the stock market crash from 17 February to 23 March as a reaction to the disaster.

One might think that combining the realized disaster with a surprise upward jump in the probability of a further disaster would bring the model closer to the data. In this case, $\ln \left(\frac{P_{\text {after }}}{P_{\text {before }}}\right)$ contains an extra term due to the change in the value of $p$ inside the bracketed expression on the right side of (4). Somewhat counterintuitively, however, the bracketed term in (4) rises with $p$ for $\theta>1$. Thus, postulating a rise in $p$ cannot reconcile the model with the data. See Section IV in Barro (2006) for a related discussion. Gabaix (2012) shows how, with Epstein-Zin preferences, to obtain a negative stock price reaction to a surprise increase in the disaster probability.

Allowing the capital structure of firms to include bonds as well as equity claims would magnify the stock price reaction to realized disasters. We do not seek to quantify the leverage effect here, but we doubt it is large enough to bring the model in line with the size of the market crash. Another potential explanation starts with the observation that traded equities are a claim on only part of the economy. On the whole, however, listed firms were better positioned than other parts of the economy to weather the pandemic and profit from pandemic-induced shifts in the structure of the economy. Thus, we do not see this line of explanation as promising.

\section{The China Experience}

Thus far, we have said little about stock prices and economic activity in China. There are good reasons to separately examine the Chinese experience. First, the pandemic erupted first in China, when little was known about the SARS-COV-2 virus. Second, after initially suppressing information about the viral outbreak in Hubei province (Kynge et al. 2020; Jacob 2020), the Chinese government imposed aggressive lockdown measures to contain the pandemic (Fig. 3). ${ }^{15}$ Third, as we will show, the dynamic between stock prices and economic activity played out differently in China than elsewhere, including other countries with relatively successful containment efforts.

\footnotetext{
${ }^{15}$ See He, Shi and Liu (2020) and Tian (2021) for detailed descriptions of China's efforts to contain the COVID-19 pandemic.
} 
Table 2 Number and market cap of listed Chinese firms

\begin{tabular}{llll}
\hline Firm type & Number of firms & $\begin{array}{l}\text { Market capitalization, tril- } \\
\text { lions of RMB }\end{array}$ & $\begin{array}{l}\text { Market cap } \\
\text { of share type }\end{array}$ \\
\hline $\begin{array}{l}\text { A Shares } \\
\text { All firms with A shares }\end{array}$ & 3740 & 59.49 & 100 \\
Those without H shares & 3621 & 46.70 & 79 \\
Those with H shares & 119 & 12.79 & 21 \\
$B$ Shares & & & 100 \\
All firms with B shares & 92 & 0.63 & 11 \\
Those without A hares & 16 & 0.07 & 89 \\
Those with A shares & 76 & 0.56 & 100 \\
H Shares & & & 17 \\
All firms with H shares & 258 & 5.09 & 83 \\
Those without A shares & 139 & 0.83 & 4.26 \\
Those with A shares & 119 & & \\
\hline
\end{tabular}

We select firms that trade actively from 2 January to 31 July 2020. The market capitalization value is based on values as of 7 August 2020. Data for A and B shares are from CSMAR, accessed on 7 August 2020. Data for $\mathrm{H}$ shares are downloaded from Yahoo Finance. We use $1 \mathrm{HKD}=0.9 \mathrm{RMB}$ to convert currencies. The total Hong Kong market cap is 38 trillion RMB, and $\mathrm{H}$ shares account for $13.5 \%$

\subsection{Sources of Data for China}

Our high-frequency proxy for economic activity in China relies on daily city-level data on residential commuting intensity from Baidu (2020),

$$
\mathrm{RCI}_{c, t}=\frac{\text { residents traveling within city } c \text { on date } t}{\# \text { of residents in city } c}
$$

We obtain the daily city-level data from the Harvard Dataverse. To construct a national mobility measure, we compute the weighted-average $\mathrm{RCI}_{c, t}$ values over 248 Chinese cities, using the number of residents in 2019 as weights. Consistent with Google's construction of workplace mobility, we use the median value from 1 to 10 January 2020 as the baseline.

Equity securities of publicly traded Chinese firms are listed on multiple exchanges and denominated in multiple currencies, as follows: A shares are listed on mainland exchanges, denominated in RMB, and traded by investors in mainland China. B shares are listed on mainland exchanges but denominated in foreign currencies. H shares are listed on the Hong Kong Stock Exchange (HKEX), denominated in HKD, and traded by investors outside mainland China. Some Chinese companies list on multiple exchanges and in multiple currencies. Table 2 reports listing counts and market capitalization in various categories. Clearly, A shares dominate listings and market capitalization. Moreover, among A shares, firms that list only on mainland exchanges account for nearly four-fifths of market cap. We consider these "A-share only" firms when relating Chinese stock prices 


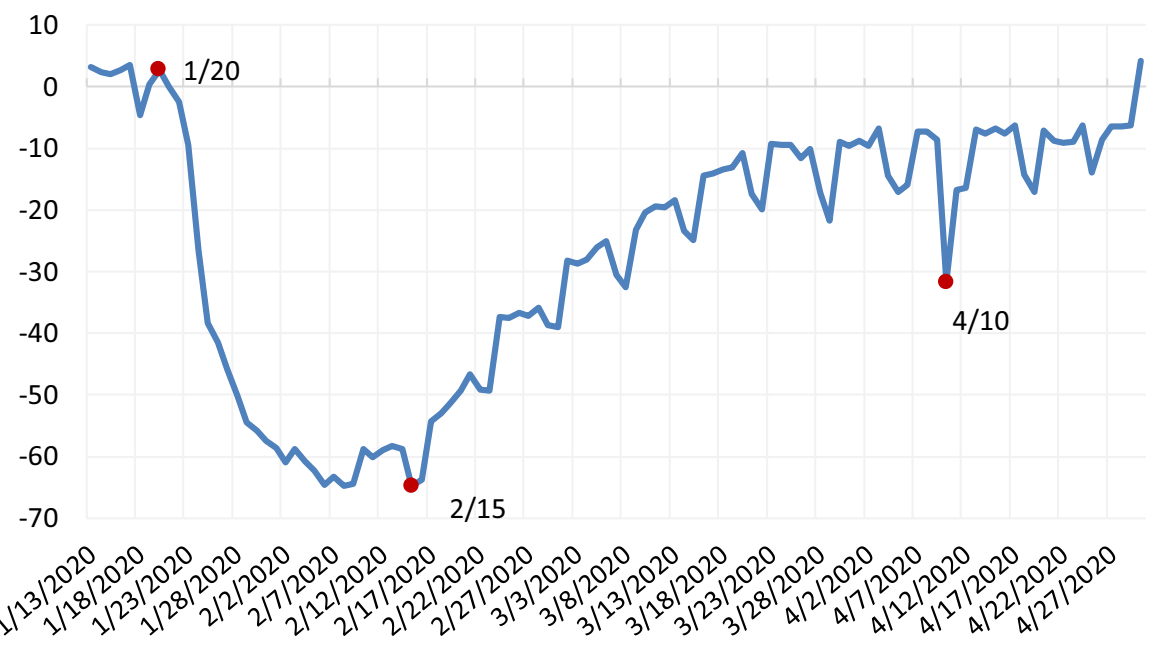

Fig. 7 China mobility, percent deviation from the baseline. Note: China mobility is defined as residents traveling at city $c$ on date $t$ over the number of residents at date $t$. In calculating the weighted average of China mobility, we use each city's number of residents in 2019 as the weight. The daily China mobility index for each city is recorded by Baidu, and we obtain the data from Harvard Dataverse, accessed on 15 August. The Baidu mobility data stopped updating since 2 May. We choose the median value of the mobility from 1 to 10 January 2020 as the baseline

to our mobility measure for China. In other investigations below, we separately consider outcomes for the Shanghai Stock Exchange (SSE) and the HKEX.

\subsection{Stock Prices and Mobility in China}

Figure 7 plots the evolution of the China mobility measure as a percent deviation from baseline. Mobility fell sharply after 20 January, bottomed out on 15 February and then recovered gradually, returning to baseline by late April. The fall in mobility on 10 April (Friday, non-holiday) is likely due to news about new COVID-19 cases among travelers from outside China. Having heard this news, Chinese residents responded with caution about visiting public places.

Figure 8 presents the time path of stock price and mobility deviations in China. Unlike other countries, stock prices do not precede declining mobility in China. Instead, the figure shows large, broadly coincident declines in stock prices and mobility from 15 January to 3 February. Mobility fell roughly $60 \%$ over this period, and stock prices fell nearly $20 \%$. The exact timing of stock price developments is obscured by the Spring Festival closure of mainland exchanges, which the government extended as part of its policy response to the pandemic. After last trading on 24 January, mainland exchanges re-opened on 3 February, with stock prices down 11 percentage points. During the market shutdown, mobility fell 34 percentage points. On 4 February, the second day after the stringency index surpassed 70, stock prices began to climb as mobility fell another 6 points. From 6 February to 4 March, mobility rose 36 points and stock prices rose 11 points. From 5 March to 30 


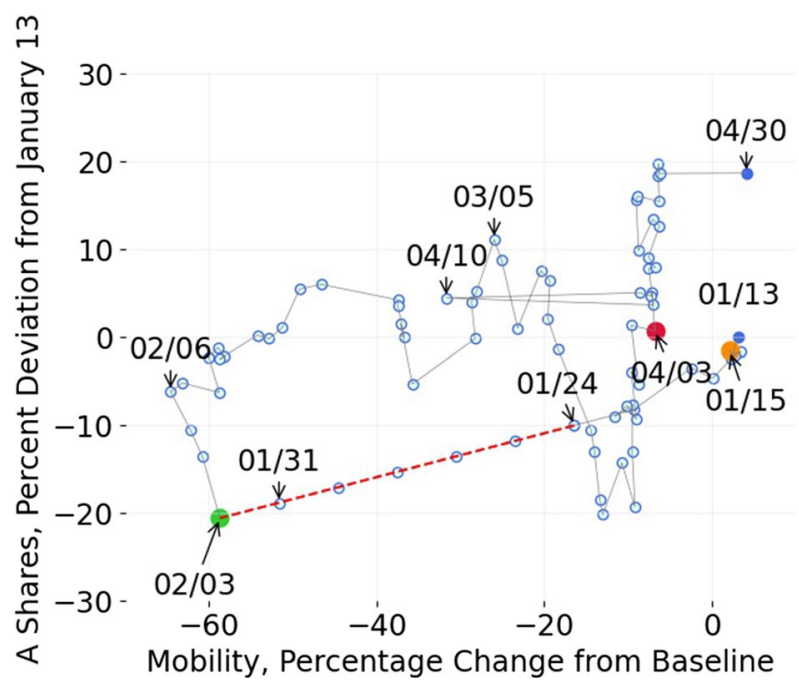

Fig. 8 Time path of china stock prices and mobility from 13 January to 30 April 2020. Note: Stock prices for A shares of companies with no H-share listing and denominated in RMB. Data are from the CSMAR dataset (China analog to WRDS). An orange diamond marks the first confirmed COVID-19 death, a green cross marks the first date with stringency index value of 70 or more, and a red dot marks the date on which the stringency index first drops below 70. We linearly interpolate stock prices from 24 January to 3 February, given that mainland China stock markets were closed from 25 January to 2 February, inclusive

April, mobility rose another 30 points and returned to baseline, while stock prices increased by 9 points.

\subsection{Comparison of Chinese and American Stock Markets}

Unlike the US stock market, the Chinese stock market attracts millions of domestic retail investors. This makes China's stock market less tied to the global financial system, but more sensitive to governmental influences (Yu and Ping 2020). Figure 9 compares cumulative log returns on Chinese and American stocks during the first four months of 2020, and Figs. 10 and 11 compare realized and implied stock market volatility over the same period. All three charts exhibit the same pattern: the coronavirus pandemic had the largest impact on the S\&P 500, a relatively modest impact on the SSE, and an intermediate effect on the Hang Seng.

Chinese authorities closed mainland stock exchanges for an extra three working days during the 2020 Spring Festival break. Accordingly, the SSE announced on 27 January 2020 that it would reopen on 3 February instead of 31 January. ${ }^{16}$ As a result, mainland markets did not register the impact of the mounting coronavirus cases in the period from 25 January through 2 February, whereas US markets

$\overline{16}$ http://www.sse.com.cn/aboutus/mediacenter/hotandd/c/c_20200202_4991648.shtml. 


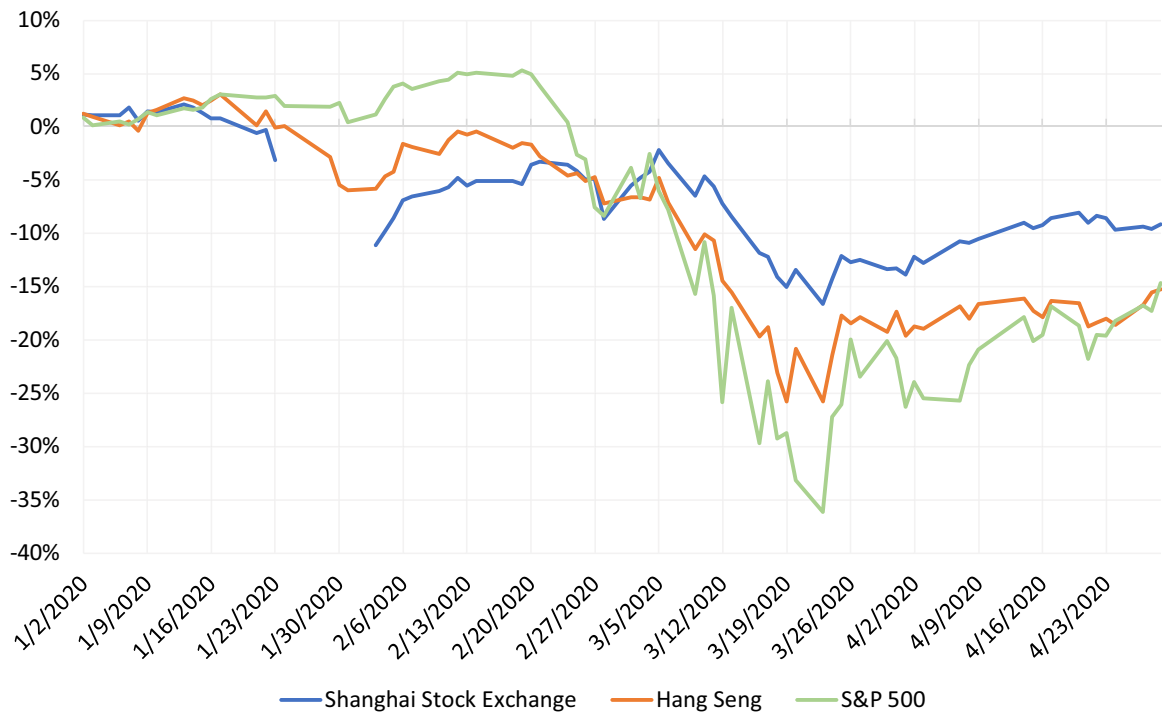

Fig. 9 Cumulative log returns on American and Chinese stocks, 2 January to 29 April 2020. Note: The figure plots cumulative log changes from 31 December 2019 for the indicated stock market indexes, using daily closing values from Yahoo Finance, downloaded on 4 May 2020. The break in blue line indicates the Spring Festival market closure in Shanghai Stock Exchange, from January 24 (Friday) to February 2 (Sunday)

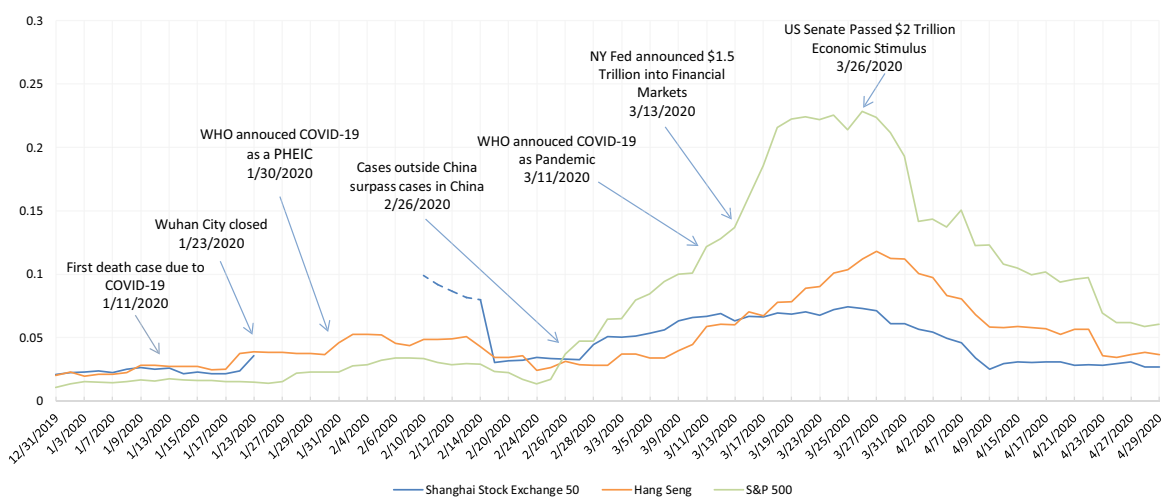

Fig. 10 Realized return volatility over past 10 trading days, American and Chinese Stocks, 31 December 2019 to 29 April 2020. Notes: We measure realized volatility as the square root of the sum of squared returns over the past 10 trading days, calculating returns as log changes in closing-price index values. We linearly interpolate over weekends and other short market closures. The break in the series for the Shanghai Stock Index reflects an extended market closure for the Chinese Spring Festival and the coronavirus pandemic, which we handle as follows: (1) Let $j=0,1,2, \ldots, N^{c}$ index days, where $j=1$ is the first closure day and $j=N^{c}$ the last closure day. (2) Treat the volatility data as missing for $j=1$ to $N^{c}+5$ and do not interpolate across these missing days. (3) For $j=N^{c}+k$ for $k=6-10$, compute past volatility by summing the squared returns over the past $k-1$ days (i.e., inclusive of the change from $k-1$ to $k$ ) and multiplying the sum by $(10 /(k-1))$. This multiplication factor adjusts for the shorter volatility window. Then, we take the square root. (4) When plotting the realized volatility data for the interval from $j=N^{c}+$ $k$ for $k=6-10$, we use a dashed line 


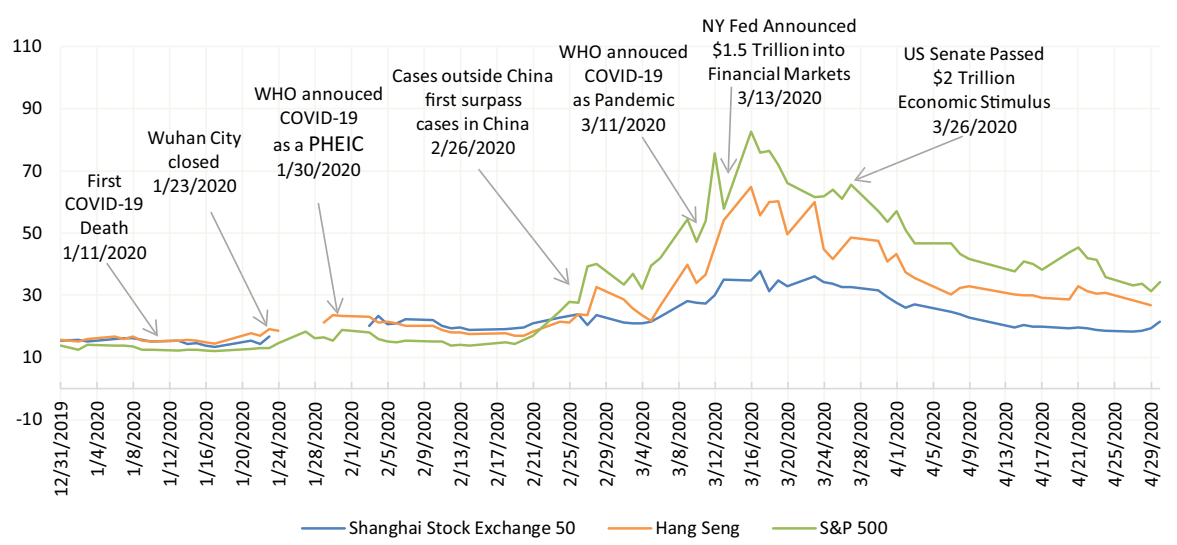

Fig. 11 Implied volatilities, American and Chinese Stock Markets, 31 December 2019 to 30 April 2020. Note: Data for the Hang Seng Volatility Index (HSI Volatility Index) and the VIX (S\&P 500) are from Yahoo Finance, downloaded on 4 May 2020. We calculated an implied volatility index for the Shanghai Stock Exchange 50 as explained in "Appendix 2," following the same approach as CBOE (2019) uses to calculate the VIX

quickly reflected new developments. The extended market closure possibly contributed to the lower volatility of Chinese stocks even after the closure itself.

Table 3 classifies the contemporaneously perceived reasons for daily stock market jumps based on explanations offered in next-day newspaper accounts, following the approach of Baker et al. (2020b). They examine next-day newspaper explanations to classify and characterize each daily move in the US stock market greater than $2.5 \%$, up or down, from 1900 to the present. Specifically, they read the lead article about each jump in next-day newspapers (or the same evening in the internet era) to classify the journalist's explanation into one of 16 categories, which include Macroeconomic News and Outlook, Government Spending, Monetary Policy, Unknown or No Explanation Offered, and Other-Specify. ${ }^{17}$ Baker et al. (2020a) extend the approach to investigate the specific role of pandemics and infectious diseases.

Panel $\mathrm{C}$ in Table 3 underscores the unprecedented impact of the COVID-19 pandemic on the US stock market. In the period before 24 February 2020-spanning 120 years and more than 1100 jumps_-next-day journalistic accounts attributed not a single daily stock market jump to infectious disease outbreaks or policy responses to such outbreaks. Perhaps surprisingly, even the Spanish Flu fails to register in next-day journalistic explanations for large daily stock market moves. There were 23 daily stock market jumps from March 1918 to June 2020, which spans the three major waves of the Spanish Flu. Next-day accounts in the Wall Street Journal attributed none of them to the Spanish Flu. Data from February 24 through the end of April tell a remarkably different story. Next-day newspaper accounts attribute 23 or 24 (depending on newspaper) of 27 US stock market jumps to news about COVID19 developments and policy responses to the pandemic.

17 The coding guide in Baker et al. (2018) describes the approach in detail. 


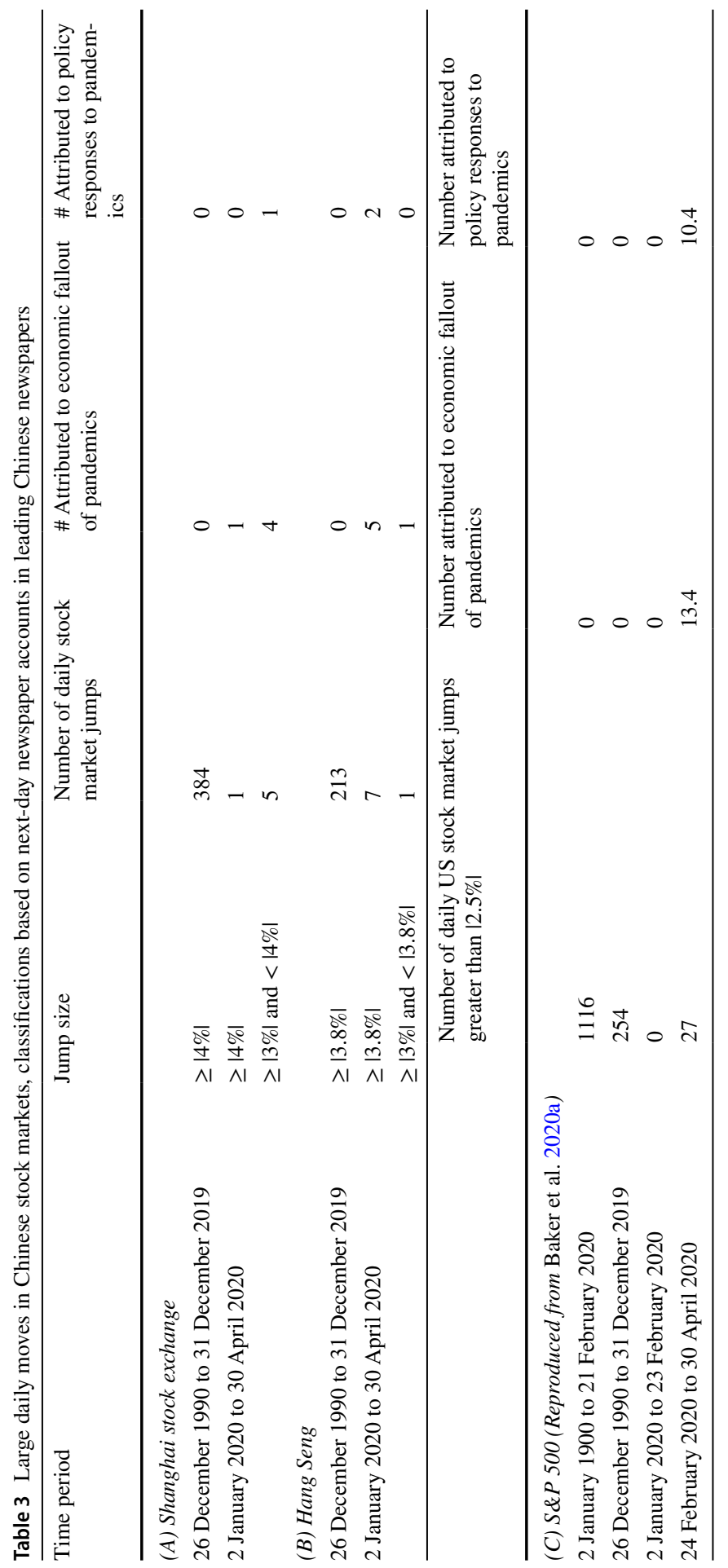

称 
We take the same approach to the Shanghai Stock Exchange and the Hang Seng from 26 December 1990 to 30 April 2020. In doing so, we tap financially oriented mainland Chinese newspapers for SSE jumps and the South China Morning Post for Hang Seng jumps. Before COVID-19, newspapers attribute zero jumps (out of hundreds) to news about infectious diseases. From 2 January to 30 April 2020, Chinese newspapers attribute all 6 daily stock market moves greater than $13 \%$ on the SSE and all 8 daily moves greater than $13.8 \%$ on the Hang Seng to the economic fallout of the pandemic or policy responses to the pandemic. ${ }^{18}$ These results closely parallel the US results. However, the incidence of large daily stock moves during the coronavirus period is several times greater for the US market than for the Chinese stock markets, in line with the extremely high volatility of the US market during this period.

To summarize, our comparison of Chinese and American stock markets during the coronavirus period uncovers four findings. First, and not surprisingly, stock prices fell less steeply in China. Second, implied and realized stock market volatility rose much more sharply in the USA than in China, particularly mainland China. Greater equity market volatility in the USA than in China from late February 2020 (and through late April) is a reversal of the usual relationship. Third, next-day newspaper accounts confirm the dominant role of pandemic-related news in driving market volatility in both countries after the onset of the pandemic. Finally, the powerful effects of pandemic-related news on stock markets are without precedent since at least 1990 in China and since 1900 in the USA.

Notes to Panel A: We consult next-day accounts of large daily stock market jumps in four Chinese newspapers: Security Times (证券时报), Security Daily (证券日报), Shanghai Security News (上海证券报), and China Security Journal (中国证券报). These four papers are the most authoritative and influential ones about securities in China. They are the first to report financial market information and are important sources of information for investors. We classify the reason for the jumps based on the explanation offered in the next-day accounts, following the approach in Baker et al. (2020b). At least one paper contains a next-day article about each large daily jump, as defined in the table. When multiple papers contain a next-day article about a given jump, they always agree as to the reason for the jump. On 3 February 2020, the first trading day after the Chinese Spring Festival, the Shanghai Stock Index fell $7.72 \%$. All four newspapers attributed the crash to the economic fallout of COVID19. The other five dates with jumps in the SSE greater than or equal to $|3 \%|$ and less than 14\% are: 28 February $2020(-3.71 \%), 2$ March $2020(3.15 \%)$, 9 March 2020 (-3.01\%), 16 March 2020 (-3.40\%) and 23 March 2020 (-3.11\%). Newspapers attributed the drops on 9, 19 and 23 March to the impact of the pandemic. On 24 March, Shanghai Securities News said the pandemic reduced external demand from Europe and the USA, causing stock prices to fall. On 17 March, Security Times reported that major central banks surprised the market and caused it to drop. On 10 March, Securities Daily attributed the A-share stock price fall to reduced demand in overseas market due to panic over oil prices and the coronavirus. On 3 March, China

18 Following Baker et al. (2020 b), we set higher jump thresholds for the SSE and the Hang Seng to adjust for their greater baseline volatility levels. 


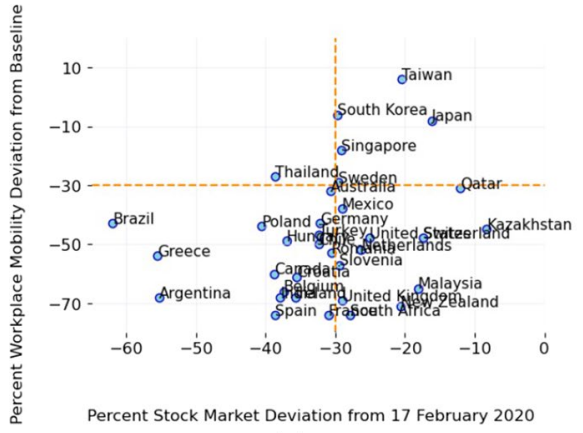

(a)

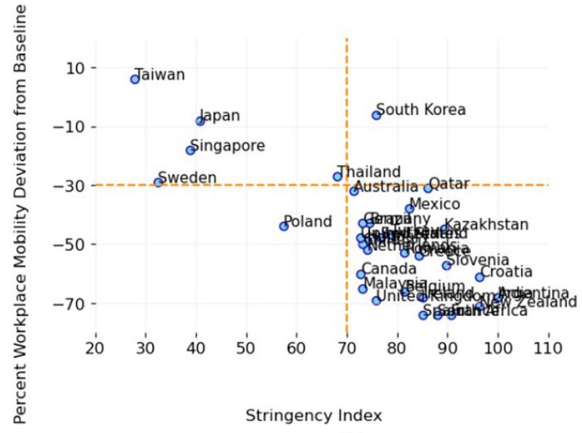

(b)

Fig. 12 Scatterplot of workplace mobility deviations against stock price deviations and stringency deviations as of 30 March 2020

Securities Journal ascribed the upward jump to the improved situation in China compared to the rest of the world. On 29 February, according to Security Times, the A-share stock price fell along with overseas stock markets due to rising new COVID cases around the world.

Notes to panel B: We consult next-day accounts of daily Hang Seng jumps in the South China Morning Post. The seven dates with market jump greater than 13.8\% in 2020 are: 9 March (-4.23\%), 16 March (-4.03\%), 18 March (-4.18\%), 20 March (5.05\%), 23 March (-4.86\%), 24 March (4.46\%) and 25 March (3.81\%). The newspapers attributed the drops on 9, 16, 18, 20 and 23 March to the impact of the pandemic, while policy stimulation boosted the market on 24 and 25 March.

Notes to panel C: Baker et al. (2020a, 2020b) consider all daily jumps in the US stock market greater than $2.5 \%$, up or down, since 1900 . They classify the reason for each jump into 16 categories based on human readings of next-day (or same-evening) accounts in the Wall Street Journal (and New York Times in 2020). Fractional counts arise when newspapers differ in their jump attribution or human readers differ in their classification of the attribution.

\subsection{What Lessons from China's Experience?}

After initially suppressing information about COVID-19, the Chinese government imposed strict lockdown measures in its efforts to contain the pandemic. It sustained these strict measures for many weeks, relaxing them somewhat in early April (Fig. 3). As we have also seen, its stock market and economic activity levels recovered more rapidly than in most other countries, including the USA. These aspects of China's experience might suggest that its willingness and capacity to impose a sustained hard lockdown explains its relative success in containing the pandemic and mitigating the economic damage. As we show next, however, China's experience is 
atypical in key respects among countries that were relatively successful in responding to the pandemic and mitigating the associated economic damage.

\section{Other Countries with Relatively Successful Early-Pandemic Experiences}

We now consider other countries with distinctively favorable early-pandemic experiences. To identify these countries, Fig. 12 plots mobility deviations against stock price deviations in panel (a) and against stringency index values in panel (b) as of 30 March 2020. That is when the global stringency index first reaches 70, our threshold for a hard lockdown.

Taiwan, Singapore, South Korea and Japan all lie in the upper right quadrant of panel (a), exhibiting relatively favorable stock price and mobility deviations. All but South Korea had comparatively low stringency values as of $30 \mathrm{March}$, as seen in panel (b). But South Korea was slow to impose a hard lockdown. It took 60 days after its first confirmed case before South Korea reached a lockdown stringency value above 70 , placing it among the bottom three countries by this measure of lockdown speed, along with Thailand and Singapore. Sweden, Japan and Taiwan did not implement a hard lockdown within our sample period.

Singapore, South Korea and Taiwan had well developed laboratory testing and medical surveillance systems in place before COVID-19 struck. Taiwan, in particular, quickly adopted containment measures in response to COVID. According to Cheng et al. (2020), "At the early stage of the outbreak, the strategy in Taiwan had three pillars: real-time surveillance with rapid risk assessment, border control and quarantine, and laboratory capacity building." Governments in South Korea and Singapore accessed mobile phone data for contact tracing purposes and virus containment. South Korea adopted an effective trace-test-treat policy (Moon 2020). In all three countries, swift government reactions, legal and technical infrastructures that supported rapid interventions, harsh penalties for violating containment rules, and high-quality health care systems were important enabling factors in responding to COVID-19 (Park et al. 2020). Japan was also relatively successful in suppressing the early wave of COVID-19 infections and its negative effects. According to Tashiro and Shaw (2020), sound governance, a strong health care system, and the socially responsible, risk-aware behavior of its citizens enabled Japan to contain infection rates while also limiting economic damage. An and Tang (2020) offer a less positive assessment of Japan's early efforts to contain the pandemic.

Recent past experiences with other epidemics prompted Singapore, South Korea and Taiwan to take steps that facilitated effective early-stage responses to COVID-19 (An and Tang 2020). The largest outbreaks of the 2003 SARS epidemic occurred in Hong Kong and mainland China (Hana and Huang 2004). Taiwan and Singapore also had large SARS outbreaks. Woo (2020) describes how the SARS episode prompted Singapore to strengthen its testing and contact tracing capabilities. Moon (2020) discusses how South Korea's painful experience 
during the 2015 MERS epidemic led to a strengthening of its trace-test-treat infrastructure.

Pinpointing the exact reasons for the distinctively favorable early-pandemic experiences of Taiwan, South Korea, Singapore and Japan (and China) is beyond the scope of this paper. What we can say-based on Fig. 12 and the other evidence summarized above-is that hard lockdowns were neither necessary nor sufficient to contain the pandemic or mitigate its economic effects. In this respect, China's experience is an outlier among the set of countries that were relatively successful in containing the pandemic and limiting its negative economic effects.

\section{Concluding Remarks}

The early stages of the COVID-19 pandemic drove a spectacular rout in stock markets. Within the space of a few weeks, value-weighted share prices fell 20 to $50 \%$ in countries around the world. The stock market implosions preceded shortterm collapses in economic activity by two to three weeks in all but 3 of the 35 countries in our sample: South Korea saw only a modest activity drop in the wake of the pandemic, and Taiwan experienced none at all. China, the first country hit by the pandemic, experienced a simultaneous collapse in stock prices and economic activity.

Conditional on global developments, national stock prices also foreshadowed the timing and severity of own-country collapses in economic activity in the wake of the pandemic. Thus, it is fair to say that stock prices exhibited strong predictive content for the collapses in economic activity that followed on the heels of the pandemic and policy responses to it. That said, we also show that the global and US stock market crashes in reaction to the pandemic are many times larger than implied by a standard asset-pricing model, given plausible values for the magnitude of the COVID-19 output disaster.

Because of its large size and status as the first country to experience a major outbreak, China's experience with COVID-19 has attracted enormous attention. China imposed strict lockdown measures and sustained them for many weeks in its (relatively) successful efforts to contain the spread of the virus. However, when we turn to other countries with distinctively favorable early-pandemic experiences, the picture looks different. Countries that moved quickly to contain the spread of the virus-with or without aggressive lockdown measures-enjoyed higher stock prices and better near-term economic performance. In short, relatively successful policy responses involved rapid implementation of virus containment efforts but not necessarily strict lockdowns on economic and social activity.

We have not delved very deeply into the factors that enabled some countries to rapidly implement an effective set of containment measures. Still, our analysis and discussion point to elements that appear to have played a positive role in this regard: costly encounters with recent past epidemics, the technical infrastructure 
needed to rapidly implement an effective test-trace-quarantine regime, a governance system that allowed for a rapid official response, a strong health care system, and governments that either enjoyed the trust and cooperation of their citizens or had the means and will to compel compliance.

\section{Appendix 1: Supplementary Material for Section 2}

See Table 4 and Figs. 13, 14, 15, 16.

Table 4 Alternative mobility measures in regressions on lagged stock price deviations, daily countrylevel data from 12 March to 23 March for the dependent variable

\begin{tabular}{|c|c|c|c|c|c|c|}
\hline \multirow[t]{2}{*}{ Coefficient estimates } & \multicolumn{4}{|c|}{ Dependent variable: $\mathrm{MD}_{c, t}$} & \multicolumn{2}{|c|}{ Dependent variable: $\Delta \mathrm{MD} c, t$} \\
\hline & (1) & (2) & (3) & (4) & $(5)$ & (6) \\
\hline \multicolumn{7}{|c|}{ (a) Using mobility deviations for transit stations as $M D_{c, t}$} \\
\hline$\alpha$ & $\begin{array}{l}0.87 * * * \\
(0.09)\end{array}$ & $\begin{array}{l}1.04 * * * \\
(0.09)\end{array}$ & $\begin{array}{l}0.49 * * * \\
(0.07)\end{array}$ & $\begin{array}{l}0.17 * \\
(0.09)\end{array}$ & & \\
\hline$\sum_{j=1}^{6} \beta^{j}$ & & & & & $1.54 * * *(0.29)$ & $1.55 * * *(0.29)$ \\
\hline Intercept & $-1.38(3.15)$ & & & & $-1.29(0.95)$ & \\
\hline Country fixed effects & No & Yes & No & Yes & No & No \\
\hline Time fixed effects & No & No & Yes & Yes & No & Yes \\
\hline Observation count & 265 & 265 & 265 & 265 & 265 & 265 \\
\hline Adjusted $R^{2}$ & 0.25 & 0.85 & 0.81 & 0.93 & 0.21 & 0.53 \\
\hline \multicolumn{7}{|c|}{ (B) Using mobility deviations for retail and recreation outlets as $\mathrm{MD}_{c, t}$} \\
\hline$\alpha$ & $\begin{array}{l}0.82 * * * \\
(0.10)\end{array}$ & $\begin{array}{l}1.14 * * * \\
(0.09)\end{array}$ & $\begin{array}{l}0.43 * * * \\
(0.08)\end{array}$ & $\begin{array}{l}0.32 * * * \\
(0.11)\end{array}$ & & \\
\hline$\sum_{j=1}^{6} \beta^{j}$ & & & & & $\begin{array}{l}1.84 * * * \\
(0.34)\end{array}$ & $\begin{array}{l}1.64 * * * \\
(0.35)\end{array}$ \\
\hline Intercept & $\begin{array}{l}-1.54 \\
(3.46)\end{array}$ & & & & $\begin{array}{l}-0.04 \\
(1.12)\end{array}$ & \\
\hline Country fixed effects & No & Yes & No & Yes & No & No \\
\hline Time fixed effects & No & No & Yes & Yes & No & Yes \\
\hline Observation count & 265 & 265 & 265 & 265 & 265 & 265 \\
\hline Adjusted $R^{2}$ & 0.20 & 0.83 & 0.74 & 0.90 & 0.14 & 0.38 \\
\hline
\end{tabular}

This table uses the same regression specifications and data as in Table 1, except for dependent variable 


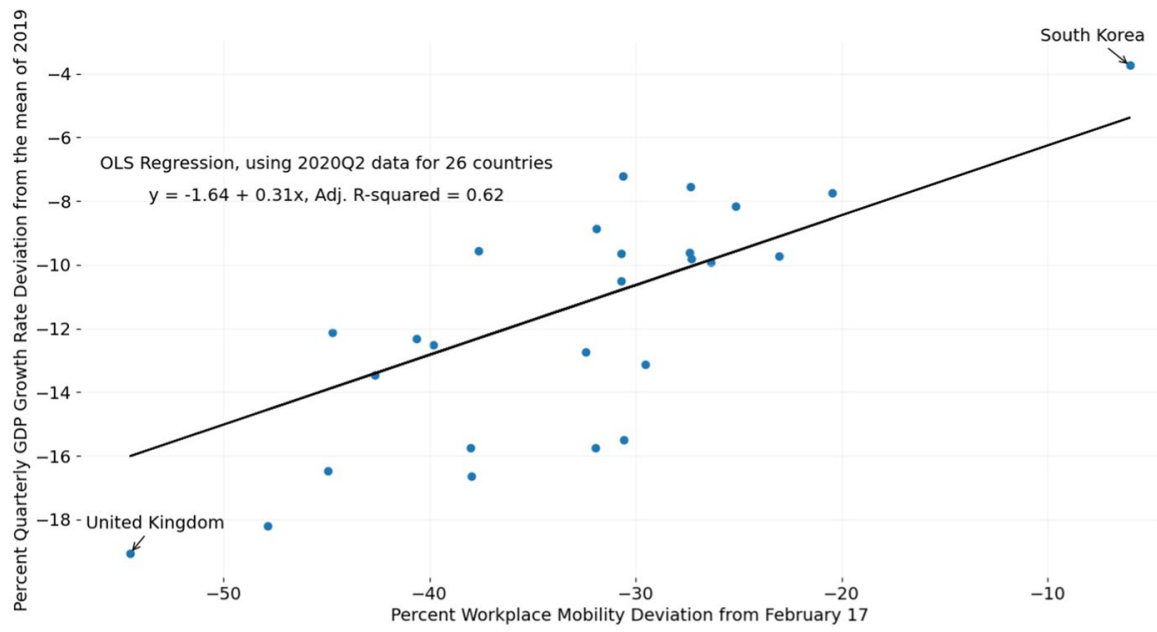

Fig. 13 Real GDP growth rate deviations and workplace mobility deviations in a cross section of countries in the second quarter of 2020. Notes: This chart considers 26 countries for which we have data on both Google's Workplace Mobility Deviation and the quarterly real GDP growth rate in the second quarter of 2020. We exclude Ireland because its GDP data are so heavily affected by net factor income from abroad associated with tax avoidance by multinational businesses. On the vertical scale, we plot the country's real GDP growth rate in the second quarter of 2020 minus its average quarterly growth rate in 2019, which we interpret as a reasonable pre-pandemic baseline for the country's real GDP growth rate. On the vertical scale, we plot the country's average daily value of the Workplace Mobility Deviation measure described in the main text

\section{Appendix 2: Constructing Implied Equity Market Volatility for China}

The Shanghai Stock Exchange (SSE) and China Securities Index Co (CSI) once published an official China VIX (iVX). The authorities suspended publication of the iVX in 201. Reuters (2018) suspects it was part of an effort by regulators to curb speculative trading and shore up investor confidence. To measure the implied volatility of China's stock market, we consulted the CBOE VIX White Paper and the SSE's method for constructing the iVX. We constructed a VIX-like index for China based on SSE 50ETF options. Our China VIX behaves very similarly to the iVX during the overlapping period, with a correlation of 0.99 .

Here is a detailed description of how we constructed our China VIX measure:

1. Select SSE 50ETF options to be used in the China VIX Index calculation. The components of our China VIX are near- and next-term put and call SSE 50ETF options. SSE 50ETF Options provide four expiration months: Current month, next month and the following consecutive quarters. We select SSE 50ETF options with an expiration day somewhat longer than 7 days as near-term, and options with the next shortest expiration day as next-term. For example, on May 19, 2020, we calculate the China VIX Index using SSE 50ETF options expiring 8 days later (i.e., "near-term") and 36 days later (i.e., "next-term"). On the following day, the SSE 50ETF options that expire in 7 days would become the "near-term" options 
A Raw Daily Data for All Days, Including Weekends and Holidays

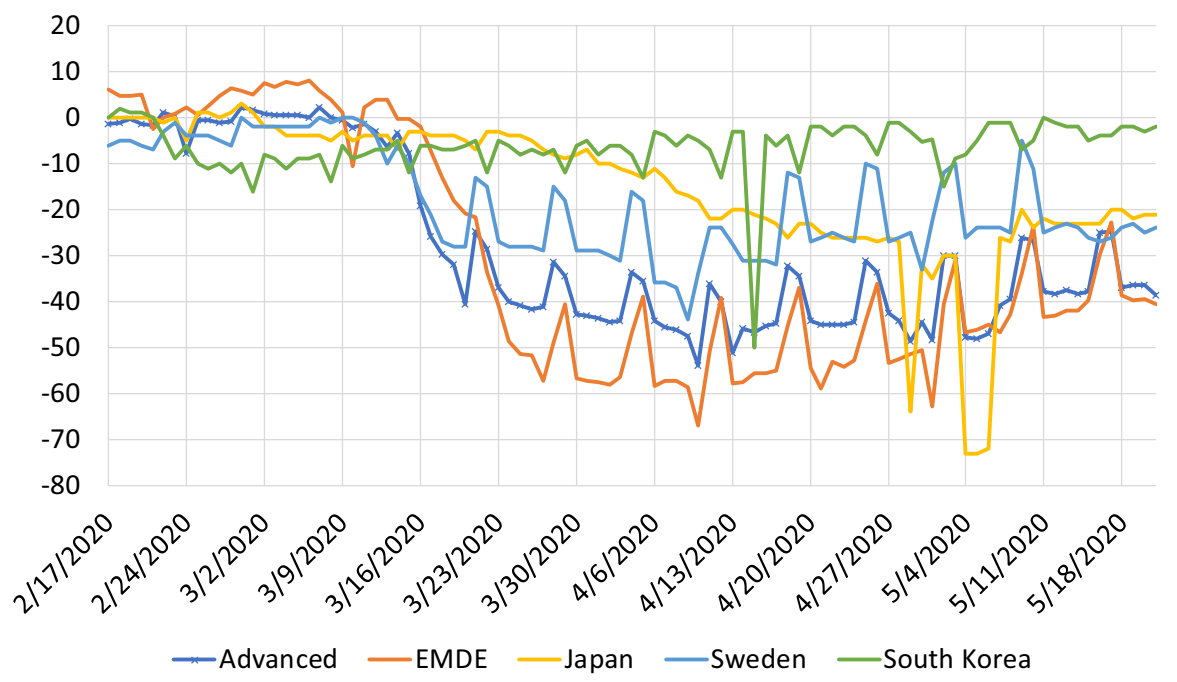

B Seven-Day Moving Average of All Days, Including Weekends and Holidays

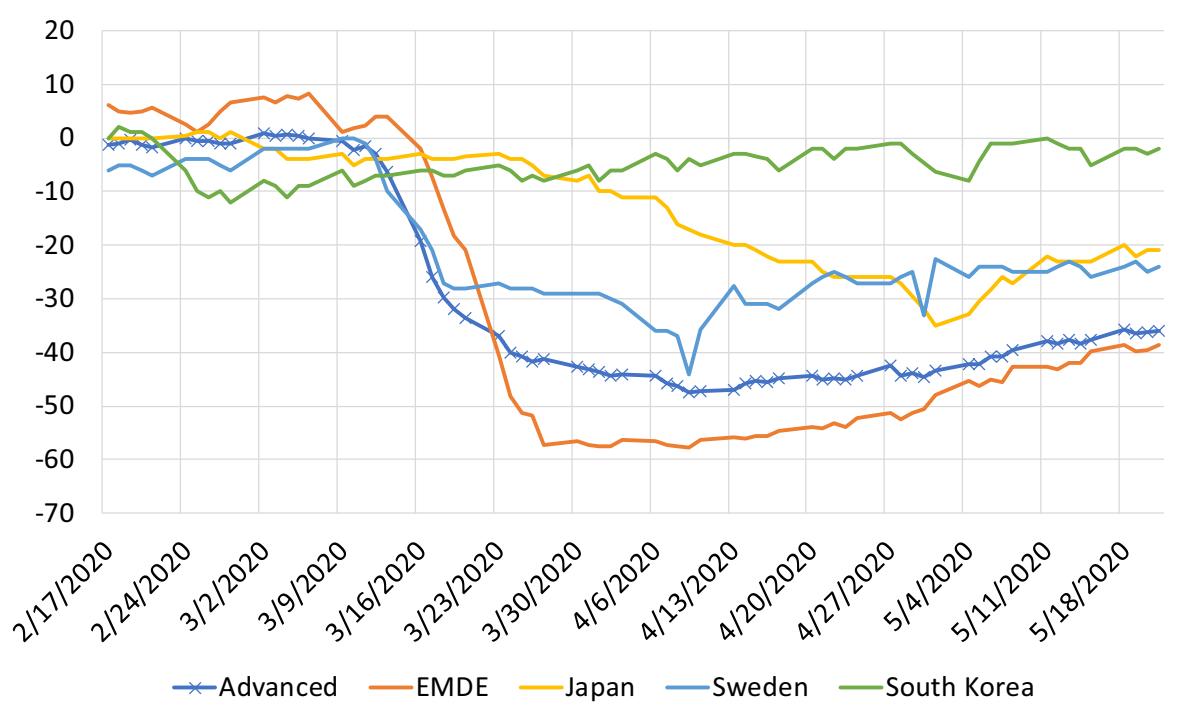

Fig. 14 Workplace mobility deviation of selected economies. a Raw daily data for all days, including weekends and holidays. b Seven-day moving average of all days, including weekends and holidays

and SSE 50ETF that expire in 35 days later would be the "next-term" options. The final selected options are out-of-the-money SSE 50ETF calls and puts centered 

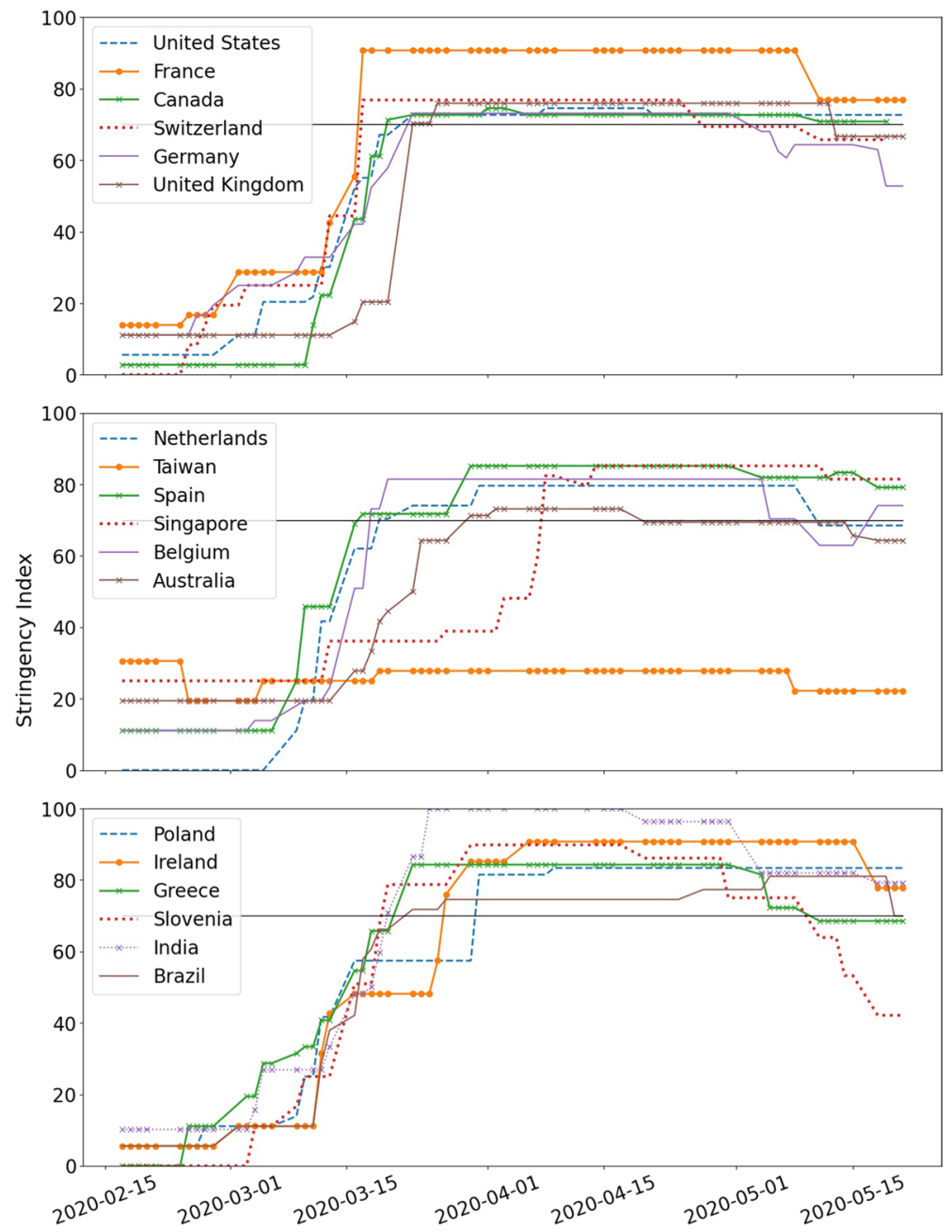

Fig. 15 Stringency of economic lockdown measures, 17 February to 21 May 2020. Note: We plot the Stringency Index from 17 February to 21 May 2020. The horizontal black line indicates the Stringency Index level of 70. The order the countries is based on the market cap on 31 December

around the at-the-money strike price, $K_{0} \cdot{ }^{19} @ @ @$ We only select options with nonzero bid prices, so the number of options used in the calculation may vary.

2. Calculate time to expiration $T_{1}$ and $T_{2}$ for near- and next-term options using the expression:

$$
T=\frac{M_{\text {current day }}+M_{\text {settlement day }}+M_{\text {other days }}}{\text { Minutes in a year }}
$$

\footnotetext{
19 SSE 50ETF Options offer nine strike prices (1 at-the-money, 4 out-of-the-money and 4 in-the-money), see .http://english.sse.com.cn/markets/derivatives/overview/.
} 

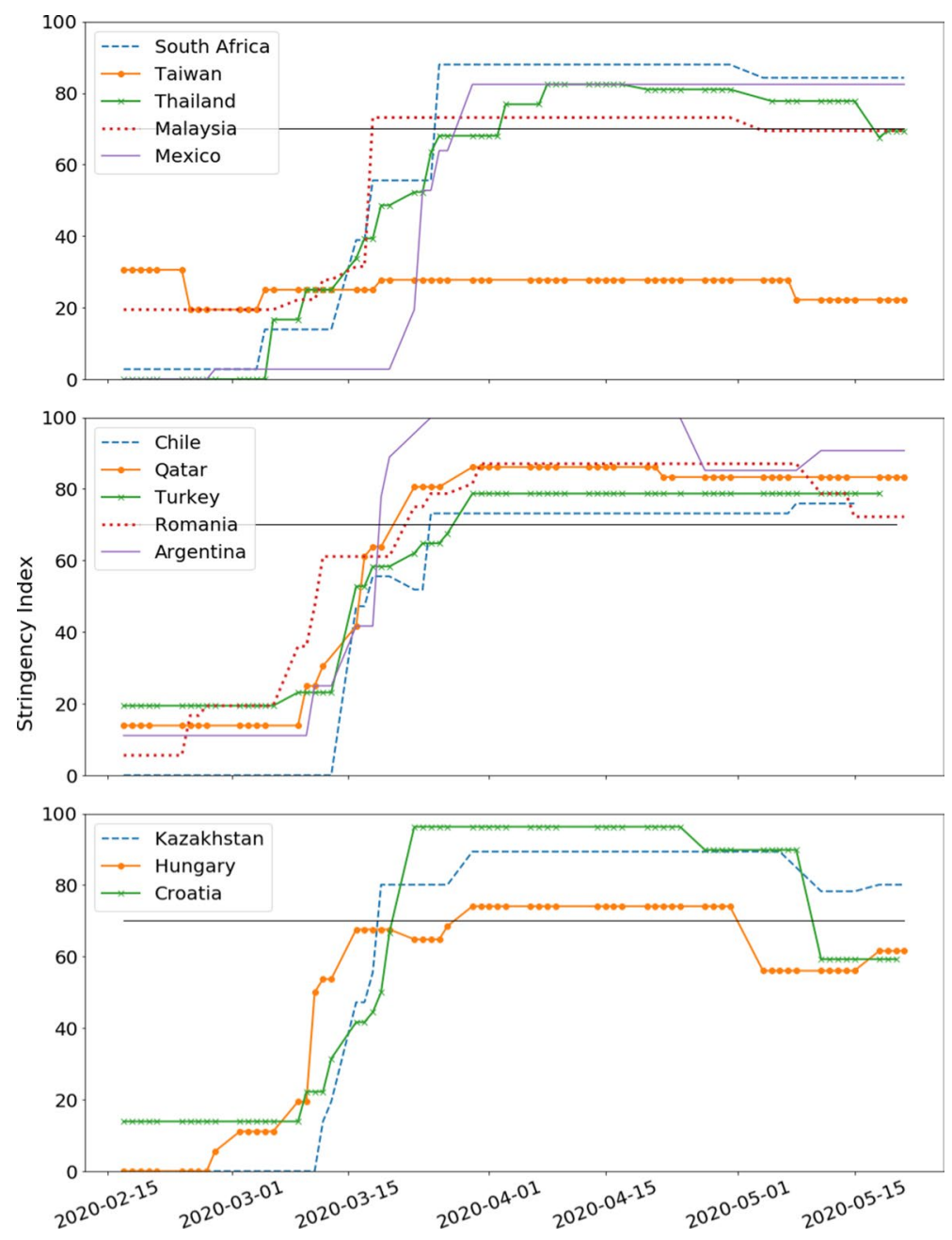

Fig. 15 (continued)

where $M_{\text {current day }}$ represents minutes remaining until midnight of the current day, $M_{\text {settlement day }}$ calculates the minutes from midnight until 9:15 am (GMT+8), and $M_{\text {other days }}$ counts total minutes from the current day to the expiration day.

3. Determine the risk-free interest rates, $R_{1}$ and $R_{2}$ for near- and next-term options. The risk-free interest rates are yields based on Shanghai Interbank Offered Rate (SHIBOR). We apply a cubic spine to derive yields on the expiration dates of relevant SSE 50ETF options.

4. Determine the forward SSE 50ETF level, $F_{1}$ and $F_{2}$, by identifying the strike price $K_{0,1}$ and $K_{0,2}$ at which the absolute difference between the call and put prices in smallest for near- and next-term options: 
Greece $(0.07 \%)$

20
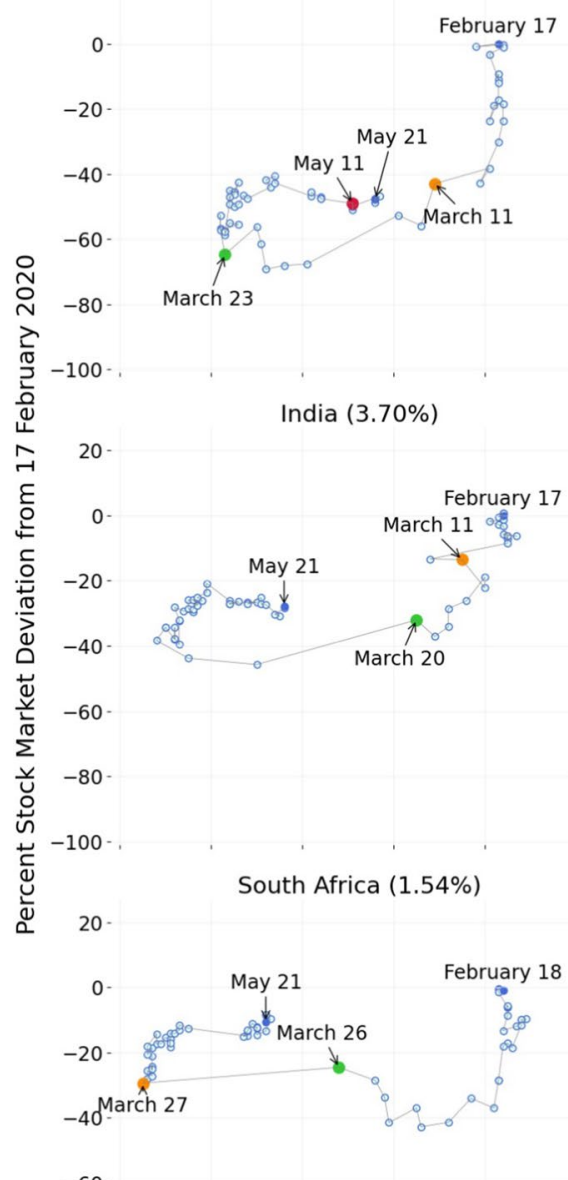

$-60$

-80 -

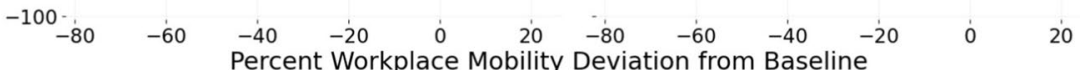

Fig. 16 Time path of stock prices and workplace mobility from 17 February to 21 May, additional countries

$$
\begin{aligned}
& F_{1}=K_{0,1}+e^{R_{1} \times T_{1}} \times\left({\text { Call } \left.\text { Price }_{1}-\text { Put }_{\text {Price }}\right)}\right) \\
& F_{2}=K_{0,2}+e^{R_{2} \times T_{2}} \times\left(\text { Call } \text { Price }_{2}-\text { Put }_{\text {Price }}\right)
\end{aligned}
$$

5. Select out-of-the-money put options with strike prices less than $K_{0,1}$ for nearterm option and put options with strike prices less than $K_{0,2}$ for next-term option. Similarly, select the out-of-the-money call options with strike prices more than $K_{0,1}$ for near-term options and put options with strike prices more than $K_{0,2}$ for 
Malaysia (0.71\%)

20
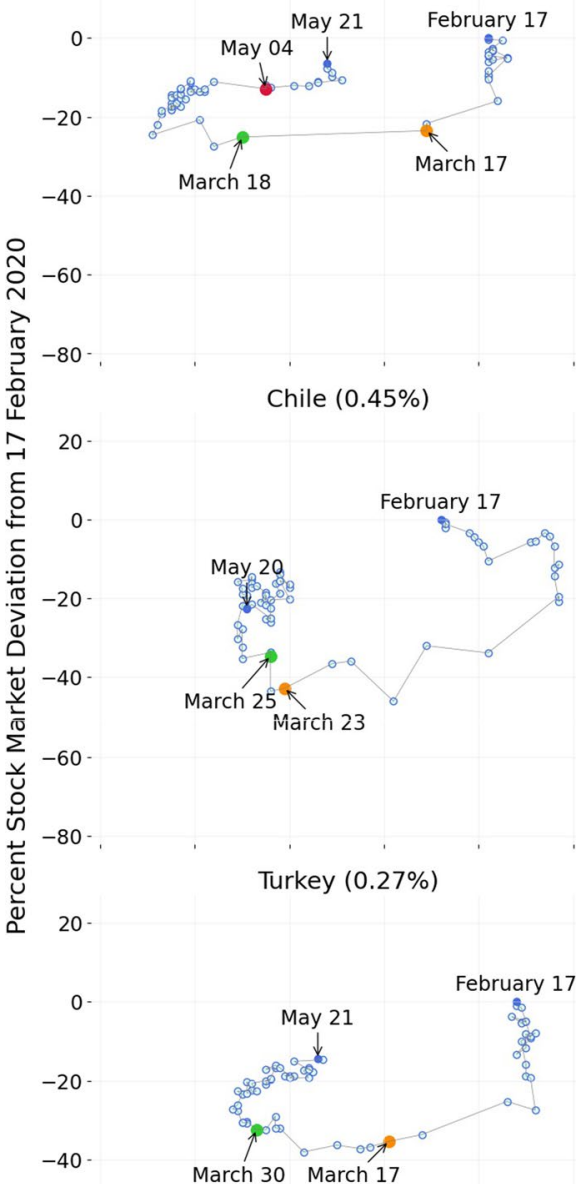

$-60$

$-80$

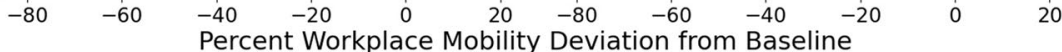

Mexico $(0.68 \%)$

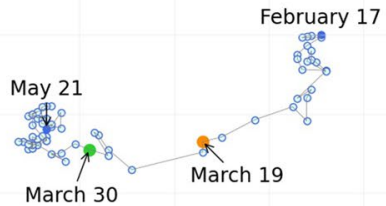

Qatar (0.29\%)

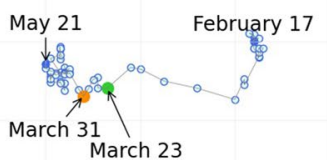

Romania $(0.25 \%)$

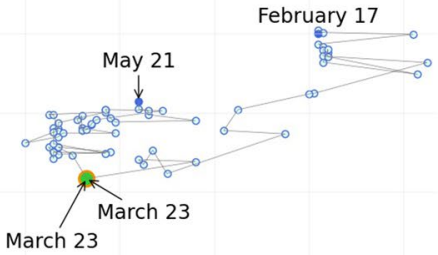

March 23

Fig. 16 (continued)

next-term options. We exclude call and pull options with zero bid prices. Finally, we select both the put and call with strike price $K_{0}$.

6. Calculate volatility for both near-term and next-term options according to 
$20-$

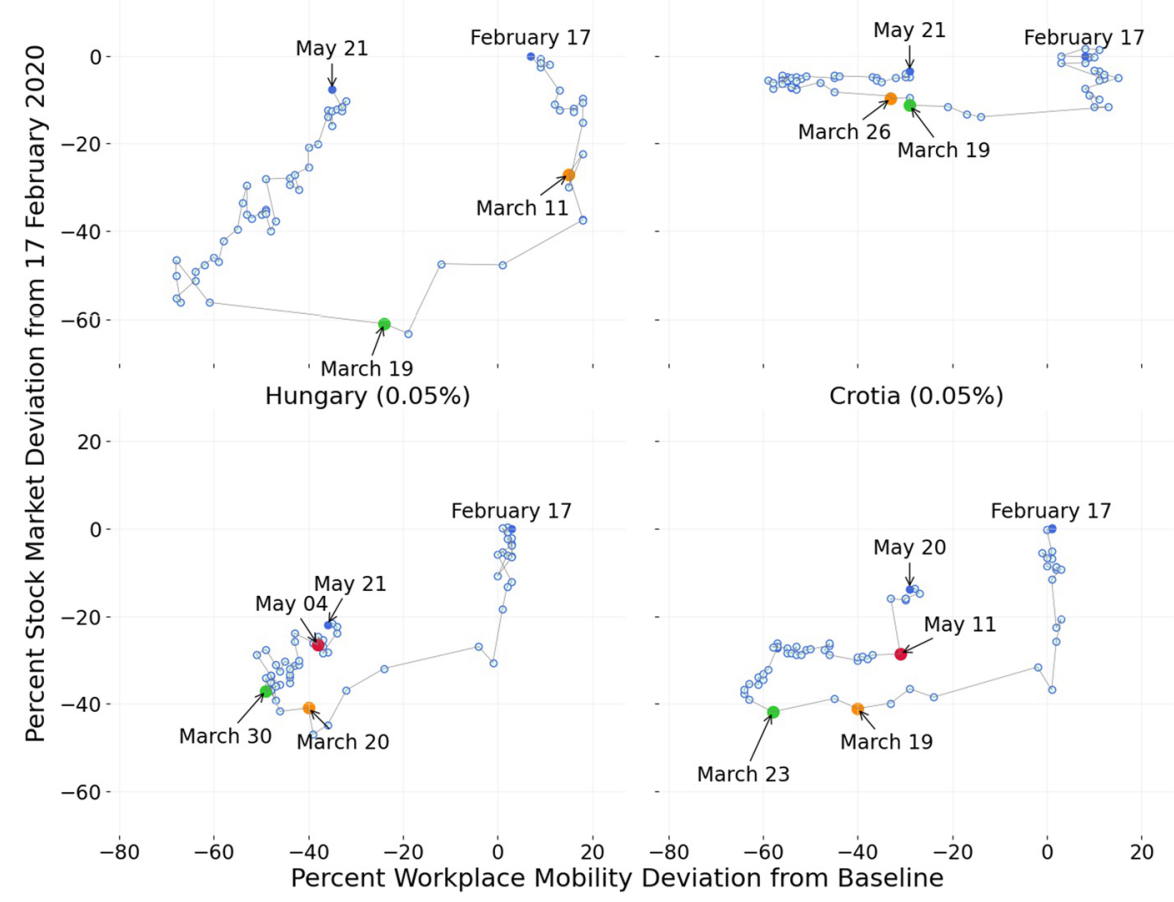

Fig. 16 (continued)

$$
\begin{aligned}
\sigma_{1}^{2} & =\frac{2}{T_{1}} \sum_{i} \frac{\Delta K_{i}}{K_{i}^{2}} e^{R_{1} \times T_{1}} Q\left(K_{i}\right)-\frac{1}{T_{1}}\left[\frac{F_{1}}{K_{0,1}}-1\right]^{2} \\
\sigma_{2}^{2} & =\frac{2}{T_{2}} \sum_{i} \frac{\Delta K_{i}}{K_{i}^{2}} e^{R_{2} \times T_{2}} Q\left(K_{i}\right)-\frac{1}{T_{2}}\left[\frac{F_{2}}{K_{0,2}}-1\right]^{2}
\end{aligned}
$$

where $\Delta K_{i}$ is half the difference between the strike prices on either side of $K_{i}$. $Q\left(K_{i}\right)$ is the midpoint of the bid-ask spread for each option with strike $K_{i}$.

7. Calculate the 30-day weighted average of $\sigma_{1}^{2}$ and $\sigma_{2}^{2}$. Then, take the square root of that value and multiply by 100 to get our China VIX Index value.

China VIX $=100 \times \sqrt{\left\{T_{1} \sigma_{1}^{2} \times \frac{M_{T_{2}}-M_{30}}{M_{T_{2}}-M_{T_{1}}}+T_{2} \sigma_{2}^{2} \times \frac{M_{30}-M_{T_{1}}}{M_{T_{2}}-M_{T_{1}}}\right\} \times \frac{M_{365}}{M_{30}}}$

where $M_{T_{1}}$ is the number of minutes to settlement of the near-term options, $M_{T_{2}}$ is the number of minutes to settlement of the next-term options, $M_{30}$ represent the number of minutes in 30 days and $M_{365}$ is the number of minutes in a $365-$ day year. 
Acknowledgements We thank Emine Boz and Linda Tesar (editors), two anonymous referees, Stefano Giglio and Li Su (discussants), Francois Gourio, Prachi Mishra, Xiao Wang, Ivan Werning and participants at the IMF's 21st Jacques Polak Research Conference and the Renmin University conference on "Structural Reforms and Economic Developments in the Face of Rising Uncertainty" for many helpful comments and suggestions. Davis thanks the U.S. National Science Foundation (SES 20180940), the Becker Friedman Institute, and the Chicago Booth School of Business for financial support. An earlier draft of this paper circulated as "Stock Prices, Lockdowns, and Economic Activity in the Time of Coronavirus."

\section{Declarations}

Conflict of interest On behalf of all authors, the corresponding author states that there are no conflicts of interest.

\section{References}

Alan, Nazli Sila, Robert F. Engle, and Ahmet K. Karagozoglu. 2020. Multi-regime Forecasting Model for the Impact of COVID-19 Pandemic on Volatility in Global Equity Markets, Available at SSRN 3646520; 15 June.

Albuquerque, Rui A., Yrjo J. Koskinen, Shuai Yang, and Chendi Zhang. 2020. Resiliency of Environmental and Social Stocks: An Analysis of the Exogenous COVID-19 Market Crash, The Review of Corporate Finance Studies, 7 July.

Alfaro, Laura, Anusha Chari, Andrew Greenland, and Peter K. Schott. 2020. Aggregate and Firm-Level Stock Returns During Pandemics, in Real Time, NBER Working Paper 26950; Apr 2.

Altig, Dave, Scott Baker, Jose Maria Barrero, Nick Bloom, Phil Bunn, Scarlet Chen, Steven J. Davis, Julia Leather, Brent Meyer, Emil Mihaylov, Paul Mizen, Nick Parker, Thomas Renault, Pawel Smietanka and Greg Thwaites. 2020. Economic Uncertainty Before and During the COVID-19 Pandemic. Journal of Public Economics. (in press). https://doi.org/10.1016/j.jeconom.2020.03.021.

Amstad, Marlen, Giulio Cornelli, Leonard Gambacorta and Dora Xia. 2020. Investors' Risk Attitudes in the Pandemic and the Stock Market: New Evidence Based on Internet Searches. BIS Bulletin 25: 66.

An, Brian Y. and Shui-Yan. Tang. 2020. Lessons from COVID-19 Responses in East Asia: Institutional Infrastructure and Enduring Policy Instruments. American Review of Public Administration 50(67): 790-800.

Baidu, China Data Lab. 2020. Baidu Mobility Data, Harvard Dataverse, V16, link.

Baker, Scott, Nicholas Bloom and Steven J. Davis. 2016. Measuring Economic Policy Uncertainty. Quarterly Journal of Economics 131(4): 1593-1636.

Baker, Scott R., Nick Bloom, Steven J. Davis, Kyle Kost, Marco Sammon and Tasaneeya Viratyosin. 2020a. The Unprecedented Stock Market Reaction to COVID-19. Review of Asset Pricing Studies 10(5): 742-758.

Baker, Scott, Nicholas Bloom, Steven J. Davis and Marco Sammon. 2018. Coding Large Daily Financial Market Moves: Data Construction Guide. https://stockmarketjumps.com/files/coding_guide_pdf. pdf.

Baker, Scott R., Nick Bloom, Steven J. Davis and Marco Sammon. 2020b. What Triggers Stock Market Jumps? working paper.

Barro, Robert J. 2006. Rare Disasters and Asset Markets in the Twentieth Century. The Quarterly Journal of Economics 121(3): 823-866.

Caballero, Ricardo J. and Alp Simsek, 2021. A Model of Endogenous Risk Intolerance and LSAPs: Asset Prices and Aggregate Demand in a 'COVID-19' Shock. Review of Financial Studies (in press). https://doi.org/10.1093/rfs/hhab036.

Chen, Long and Michael Spence. 2020. Five Lessons from Tracking the Global Pandemic Economy, VoxEU CEPR Policy Portal, 17 July.

Cheng, Hao-Yuan., Shu-Ying. Li and Chin-Hui. Yang. 2020. Initial Rapid and Proactive Response for the COVID-19 Outbreak-Taiwan's Experience. Journal of the Formosan Medical Association 119(4): 771 .

Chicago Board of Options Exchange (CBOE). 2019. White Paper: CBOE Volatility Index, available here.

Cox, Josue, Greenwald, Daniel L. and Ludvigson, Sydney C. 2020. What Explains the COVID-19 Stock Market? NBER Working Paper 27784. 
Davis, Steven J., Stephen Hansen and Cristhian Seminario. 2020. Firm-Level Risk Exposures and Stock Price Reactions to COVID-19, NBER Working Paper 27867.

Deb, Pragyan, Davide Furceri, Jonathan Ostry and Nour Tawk. 2020. The Effects of Containment Measures on the COVID-19 Pandemic. Covid Economics: Vetted and Real-Time Papers 19: 53-86.

Ding, Wenzhi, Ross Levine, Chen Lin and Wensi Xie. 2020. Corporate Immunity to the COVID-19 Pandemic, NBER Working Paper 27055.

Egert, Balazs, Yvan Guillemette, Fabrice Murtin and David Turner. 2020. Walking the Tightrope: Avoiding a Lockdown while Containing the Virus, CESifo working paper 8797 (December).

Ferguson, Niall. 2020. 1918, 1957, 2020: Big Pandemics and their Economic, Social and Political Consequences, working paper, 20 May.

Gabaix, Xavier. 2012. Variable Rare Disasters: An Exactly Solved Framework for Ten Puzzles in MacroFinance. Quarterly Journal of Economics 127(2): 645-700.

Giglio, Stefano, Matteo Maggiori, Johannes Stroebel and Stephen Utkus. 2021. The Joint Dynamics of Investor Beliefs and Trading During the COVID-19 Crash. In: Proceedings of the National Academy of Sciences of the United States of America, 118, no. 4 (January).

Google. 2020. COVID-19 Community Mobility Reports at www.google.com/covid19/mobility/.

Gormsen, Niels J. and Ralph Koijen. 2020. Coronavirus: Impact on Stock Prices and Growth Expectations. Review of Asset Pricing Studies 10(4): 574-597.

Hale, Thomas, Sam Webster, Anna Petherick, Toby Phillips, and Beatriz Kira. 2020. Oxford COVID19 Government Response Tracker, Blavatnik School of Government, at www.bsg.ox.ac.uk/research/ research-projects/coronavirus-government-response-tracker.

Hana, Donald and Yiping Huang. 2004. The Impact of SARS on Asian Economies. Asian Economic Papers 3(1): 102-112.

Hassan, Tarek A., Stephan Hollander, Laurence van Lent and Ahmed Tahoun. 2020. Firm-Level Exposure to Epidemic Diseases: COVID-19, SARS, and H1N1, NBER Working Paper 26971.

He, Alex J., Yuda Shi and Hongdou Liu. 2020. Crisis Governance, Chinese Style: Distinctive Features of China's Response to the COVID-19 Pandemic. Policy Design and Practice 3(3): 242-258.

Jacob, Jabin T. 2020. “To Tell China’s Story Well’: China’s International Messaging during the COVID19. China Report 56(3): 374-392.

Johns Hopkins University. 2020. COVID-19 Data Repository, Center for Systems Science and Engineering, at https://github.com/CSSEGISandData/COVID-19/tree/master/csse_covid_19_data.

Kynge, James, Sun Yu and Tom Hancock. 2020. Coronavirus: The Cost of China's Public Health CoverUp, Financial Times, 6 February 2020.

Landier, Augustin and David Thesmar. 2020. Earnings Expectations during the COVID-19 Crisis. Review of Asset Pricing Studies 10(4): 598-617.

Lucas, Robert E. 1978. Asset Prices in an Exchange Economy. Econometrica 96: 1429-1445.

Mehra, Rajnish and Edward Prescott. 1985. The Equity Premium: A Puzzle. Journal of Monetary Economics 15: 145-161.

Moon, M. Jae. 2020. Fighting COVID-19 with Agility, Transparency, and Participation: Wicked Policy Problems and New Governance Challenges. Public Administration Review 80(4): 651-656.

Pagano, Marco, Christian Wagner and Joseph Zechner. 2020. Disaster Resilience and Asset Prices, arXiv preprint arXiv:2005.08929, 22 May.

Papanikolaou, Dimitris and Lawrence D.W. Schmidt. 2020. Working Remotely and the Supply-Side Impact of COVID-19, NBER Working Paper 27330.

Park, Sangchul, Gina Jeehyun Choi and Haksoo Ko. 2020. Information Technology-based Tracing Strategy in Response to COVID-19 in South Korea-Privacy Controversies. JAMA 323(21): 2129-2130.

Ramelli, Stefano and Alexander F. Wagner. 2020. Feverish Stock Price Reactions to COVID-19, Swiss Finance Institute Research Paper No. 20-12, 21 April.

Rietz, Thomas A. 1988. The Equity Risk Premium a Solution. Journal of Monetary Economics 22(1): $117-131$.

Sampi, James and Charl Jooste. 2020. Nowcasting Economic Activity in Times of COVID-19: An Approximation from the Google Community Mobility Report. World Bank Policy Research Working Paper 9247.

Shiller J. Robert. 2020. Understanding the Pandemic Stock Market, Project Syndicate, 7 July.

Tashiro Ai and Rajib Shaw. 2020. COVID-19 Pandemic Response in Japan: What is Behind the Initial Flattening of the Curve?". Sustainability 12(13): 5250.

Tian, Wei. 2021. How China Managed the COVID-19 Pandemic. Asian Economic Papers 20(1): 75-101. 
Velde, Francois. 2020. What Happened to the US Economy During the 1918 Influenza Pandemic? A View Through High-Frequency Data, Federal Reserve Bank of Chicago Working Paper 2020-11, 17 April.

Wachter, Jessica. 2013. Can Time-Varying Risk of Rare Disasters Explain Aggregate Stock Market Volatility? Journal of Finance 68(3): 987-1035.

Woo, J.J. 2020. Policy Capacity and Singapore's Response to the COVID-19 Pandemic. Policy and Society 39(3): 345-362.

World Health Organization, 2005. Strengthening Health Security by Implementing the International Health Regulations. https://www.who.int/ihr/procedures/pheic/en/\#.

Yu, Xie and Chong Koh Ping. 2020. 'It Is All About Faith': Eager Small Investors Buoy China Stocks in Market Maelstrom. Wall Street Journal 6: 66.

Zarembra, Adam, Renatas Kizys, David Y. Aharon and Ender Demir. 2020. Infected Markets: Novel Coronavirus, Government Interventions, and Stock Return Volatility around the Globe. Finance Research Letters 35: 101597.

Publisher's Note Springer Nature remains neutral with regard to jurisdictional claims in published maps and institutional affiliations.

Steven J. Davis is the William H. Abbott Distinguished Service Professor of International Business and Economics at The University of Chicago Booth School of Business and Senior Fellow at the Hoover Institution.

Dingqian Liu is a Ph.D. student at American University.

Xuguang Simon Sheng is Associate Professor of Economics at American University. 